\title{
Os sentidos da Facada em Jair Bolsonaro: uma Análise Sociocibernética de Redes Sociais no Twitter
}

\author{
The Meanings of Jair Bolsonaro's Stabbing: An Sociocybernetics \\ Network Analysis on Twitter
}

Los sentidos de la puñalada em Jair Bolsonaro: um Análisis Sociocibernética de Redes Sociales en Twitter

\section{Otávio Iost Vinhas}

Doutorando em Estudos da Informação e Comunicação pela University College Dublin (UCD), Irlanda. Pesquisador do Laboratório MIDIARS (Grupo de Pesquisa em Mídia, Discurso e Análise de Redes Sociais), Brasil. E-mail: otavio.vinhas@gmail.com

\section{Resumo}

Este artigo objetiva descrever a dinâmica de construção de significados em relação ao evento da "facada" no então candidato à presidência do Brasil, Jair Bolsonaro, no Twitter. Nesse sentido, propondo uma metodologia de Análise Sociocibernética de Redes Sociais, combina-se métodos computacionais de Análise de Redes Sociais a uma abordagem teórico-epistemológica construtivista, voltada à comunicação na sociedade como uma operação complexa. Assim, descreve-se, longitudinalmente, a partir de três lapsos temporais analisados, como ocorreram modificações de significados acerca da facada em Jair Bolsonaro no Twitter. Observou-se como, ao longo do tempo, as diferentes perspectivas produzidas inicialmente sobre o evento sintetizaram-se em uma polarização política guiada por valores. Dessa forma, a complexidade em torno da facada foi organizada em duas verdades relacionais em oposição: como algo forjado ou como tentativa de homicídio.

Palavras-chave: facada; Jair Bolsonaro; análise sociocibernética de redes sociais; ciência social computacional; twitter.

\footnotetext{
O presente artigo apresenta resultados da dissertação de mestrado intitulada "Os sentidos da "facada" em Jair Bolsonaro: uma análise de redes culturais online à luz da Teoria dos Sistemas de Niklas Luhmann” (Vinhas, 2019), realizada no Programa de Pós-Graduação em Sociologia da Universidade Federal de Pelotas (PPGS/UFPel), sob a orientação do Prof. Dr. Léo Peixoto Rodrigues - a quem gostaria de registrar o meu imenso agradecimento. O trabalho possuiu o apoio da Coordenação de Aperfeiçoamento de Pessoal de Nível Superior - Brasil (CAPES).
} 


\section{Introdução}

Na última eleição presidencial ocorrida no Brasil, em 2018, um dos casos de maior notoriedade, tanto pela relevância para a disputa eleitoral quanto pela geração de controvérsias no debate público, foi o atentado da "facada" em Jair Bolsonaro. Relembra-se: no dia 06/09/2018 (seis de setembro de dois mil e dezoito), na cidade de Juiz de Fora, Minas Gerais, o então candidato, que naquele momento liderava as pesquisas eleitorais, participava de carreata para promover a sua campanha. Nesse momento, quando um homem, identificado como Adélio Bispo, aproximou-se de Jair Bolsonaro e, em meio à multidão de pessoas que o acompanhava, lhe atacou com uma faca no abdômen.

Daquele momento em diante, o evento relativo à "facada" passou a ser significado na sociedade de modo heterogêneo, a partir da formação de diversas narrativas e opiniões. A complexidade do evento para o contexto sociopolítico brasileiro naquele momento, somada à aleatoriedade desse tipo de acontecimento a um candidato à presidência do país, fomentou a constituição de diversos pontos de vista divergentes. Isso foi visto em larga escala nas interações mediadas por plataformas de mídias digitais - principalmente ao considerar-se que, naquele momento, Jair Bolsonaro liderava as pesquisas de opinião na corrida eleitoral. Em razão disso, o processo comunicacional de significação da "facada" na sociedade, em sua integralidade, procedeu-se de modo fragmentado, caracterizado por uma dinâmica de intensa instabilidade em que, ao longo do tempo, diversas novas narrativas - comunicadas como "verdades" - foram sendo edificadas no ciclo contínuo das interações sociais.

Esse é apenas mais um dos vastos exemplos sobre a necessidade de o campo científico aprofundar-se em problemáticas relacionadas às características da constituição da sociedade frente às dinâmicas sociais constituídas com e na internet. Sobretudo no Brasil, apesar do recente avanço, as pesquisas sociais apoiadas em métodos computacionais ainda são relativamente incipientes. Em razão disso, observa-se, gradualmente, a emergência de pesquisas vinculadas à Ciência Social Computacional, utilizando-se da ampla capacidade informacional de coleta, processamento e análise de quantidades de dados para abordar questões socialmente complexas.

Assim, o objetivo deste artigo é descrever a dinâmica de construção de significados em relação ao evento da "facada" no então candidato à presidência do Brasil, Jair Bolsonaro, no Twitter. Nesse sentido, a proposta articulada está voltada à complexidade do processo comunicativo, utilizando-se da combinação de métodos computacionais e teoria sociológica para observar um objeto de conhecimento constituído frente à contingência e indeterminação que configuram as relações sociais da sociedade contemporânea. 
$\mathrm{O}$ artigo encontra-se organizado em três partes. Na primeira, apresenta-se a lente teóricoepistemológica sob a qual se observa o fenômeno da comunicação contemporânea, a partir da ideia de complexidade suscitada nos estudos da Sociocibernética. Na segunda parte, é exposta a metodologia, a qual chamamos de Análise Sociocibernética de Redes Sociais, proposta para a coleta, filtragem, análise e descrição dos dados constituídos para este artigo. Na terceira e última parte, discute-se os resultados obtidos frente ao objetivo do artigo, centrado em descrever os significados produzidos acerca da facada em Jair Bolsonaro no Twitter, com base em três momentos de análise distintos.

\section{Por uma lente sociocibernética da sociedade: a comunicação como complexidade}

O presente trabalho está alicerçado em uma lente teórico-epistemológica vinculada à sociocibernética (Almanaguer-Kalixto; Giglietto, 2019; Altmann; Peters, 2018). Através desse escopo, compreende-se a comunicação com base nos conceitos de complexidade e de autoorganização, conforme desenvolvimentos suscitados pela Teoria dos Sistemas de Niklas Luhmann (1995; 2000; 2006). De modo geral, a sociocibernética consiste em uma abordagem interdisciplinar, vinculando os diferentes campos das Ciências Sociais a disciplinas e métodos variados, como as ciências da cognição, as ciências da complexidade, bem como às áreas voltadas à análise de redes sociais (Hornung, 2019).

Partindo desse prisma, entende-se o que é comunicação em contraste a uma concepção meramente mecânica, remetente à mera transmissão de mensagens de um ponto a outro. Da mesma forma, rejeita-se a proposta de que a comunicação permite ou tende à construção de consensos através de diálogos fomentados pela intersubjetividade humana - no modelo inicial de uma "esfera pública" (Habermas, 1989).De modo geral, entende-se a comunicação como uma operação de seleção de sentidos em que, diante da complexidade inapreensível do mundo, algo apenas pode ser assimilado e propagado a partir de um ponto cego, isto é, quando um horizonte de outras possibilidades é excluído do processo comunicativo (Luhmann, 2006).

Isso se dá porque, ao incluir a noção sistêmica de complexidade na comunicação, a realidade deixa de figurar como algo hipoteticamente tangível por uma consciência. Não se nega, todavia, que o mundo existe como de modo uníssono a todos os seus possíveis constituintes (observadores), no entanto, paradoxalmente, esse mesmo mundo passa a ser visto de modo particular (único) por cada unidade sistêmica inserida nele (Luhmann, 2006). Isso ocorre em razão da complexidade inacessível da realidade, de modo que a emergência de um sistema sempre estará associada a uma forma específica de construção de um olhar sobre o mundo. 
Assim, no sentido dado por Luhmann (2006), a(s) realidade(s) é/são (re)produzida(s) comunicativamente - e não propriamente dada de modo concreto -, uma vez que a sua construção ocorre continuadamente sob as acepções teóricas/cognitivas daqueles que a(s) coorganiza(m).

Pensando em relação a como, contemporaneamente, a complexidade da comunicação está organizada através de redes sociais, Stephan Fuchs (2009) entende que as redes são onde se dão as dinâmicas de produções de significados na sociedade. $\mathrm{O}$ autor entende que redes sociais são comunicações sistêmicas em que é gerado um "padrão holístico de significados simbolicamente inter-relacionados e mais ou menos imbricados" (Fuchs, 2009:347). Esse entendimento assemelha-se ao de White (2008), para quem as redes sociais tratam-se de agrupamentos semânticos interconectados entre si, que emergem por relações de semelhança (aproximação) e de diferença (afastamento). A lógica das redes sociais, nesse caso, prescreve que as variações relacionais entre diferentes grupos, responsáveis por definir os posicionamentos em uma rede de comunicações/interações, são estabelecidas conforme as possibilidades de contingenciar identidades e/ou valores sociais por um ou mais agrupamentos, como forma de reduzir a complexidade imanente do mundo (Rodrigues; Neves, 2017).

A dinâmica de produção dos significados na sociedade, a partir disso, compreende uma cadeia de múltiplas interações sistêmicas (redes), desenvolvidas em constante atualização, em relação a comunicações anteriores (Bastos, 2011). Em vista às interações no âmbito digital, Bastos (2014) descreve que os significados produzidos nas redes de comunicações partem, conjuntamente, da convergência de sentidos entre diferentes mensagens comunicadas, bem como das configurações auto-organizacionais específicas de uma plataforma digital (Twitter, Facebook, Whatsapp). Em razão disso, a produção de significados nas redes digitais compreende um movimento essencialmente coletivo, em que as seleções acerca de quais sentidos acerca da realidade são comunicados, selecionados e produzidos descentralizadamente, por meio da “clusterização” entre interações semanticamente convergentes (Bastos, 2014).

Fenômenos como a desinformação e a polarização, sob essa ótica, não são diretamente causados pela tendência de descentralização das formas de comunicar ou simplesmente pelo espalhamento de mentiras em escala. Suscintamente, o que se observa é a emergência de um ecossistema de crise epistêmica (Oliveira, 2020), circunstanciada pelo aumento de complexidade catastrófico no processo comunicativo, catalisado pela dimensão do digital (Baecker, 2007). Nessa lógica, vê-se a formação do que Cesarino (2020) descreve como um contexto de pósverdade em que a condição epistêmica de qualquer enunciado no processo comunicativo pode ser modificada por qualquer interagente a um custo muito baixo. Todavia, essa lógica não 
implica, necessariamente, em um esvaziamento total acerca da possibilidade de se estabelecer uma "verdade". Dada a complexidade assumida pela realidade possível de ser conhecida, a ideia de verdade passa a se tornar inevitavelmente vinculada às amplas variações sociais e/ou cognitivas presentes no processo comunicativo contemporâneo (Luhmann, 1995), Assim, o estabelecimento de uma verdade passa a ocorrer sempre de modo contingente e precário, adstrito a aspectos contextuais e relacionais, principalmente quando se refere à lógica de construção de sentido operada nas redes sociais digitais.

\section{Metodologia}

\section{A proposta de uma Análise Sociocibernética de Redes Sociais}

Tendo isso em vista, propõe-se o método de uma "Análise Sociocibernética de Redes Sociais" no Twitter, mediante a associação do arcabouço teórico-epistemológico da sociocibernética e as técnicas computacionais de análise de redes desenvolvidas para a descrição das interações sociais na internet. Busca-se formular uma proposta pertinente à dinâmica de produção e às estruturas de significados construídos nas redes digitais de interação ao longo do tempo. Propõe-se, assim, um modo de observar tais questões, tendo em vista a caracterização da sociedade contemporânea pela diferenciação, na qual emergem novas formas de produzir e, portanto, de estabilizar diferentes formas e/ou perspectivas semânticas através das quais a sociedade observa a si mesma. A seguir, descreve-se a lógica desta proposta metodológica.

Esta formulação metodológica envolve a combinação entre dois métodos: a Análise de Redes Sociais na internet (ARS) e a abordagem da Análise de Redes Culturais (ARC). Na direção do que se propôs em trabalho anterior (Vinhas, 2019), pretende-se estabelecer uma aproximação dos aportes técnicos e teóricos da ARS, utilizados para os estudos computacionais de redes sociais online, à perspectiva da sociocibernética apoiada na ARC, cujo enfoque direciona-se a uma investigação sistêmica relativa às dinâmicas estabelecidas entre coocorrências semânticas em interações.

Neste trabalho, a aproximação entre essas duas abordagens direciona-se à investigação das informações produzidas e difundidas nas interações sociais desenvolvidas no Twitter. Tendo isso em vista, a aproximação entre essas duas abordagens é proposta no sentido de potencializar o enfoque analítico e computacional da ARS, conforme utilizada por Recuero (2017), a uma visão teórico-epistemológica vinculada à sociocibernética, observada no modelo de Fuhse (2015a). 
Dessa forma, a Análise Sociocibernética de Redes Sociais inclui procedimentos mistos, envolvendo abordagens de caráter quantitativo e qualitativo. O procedimento quantitativo, fundamentado na ARS, abrange a coleta, a seleção e a classificação dos dados, bem como a elaboração de grafos que ilustram as estruturas das redes das interações sociais no Twitter. Complementarmente, o procedimento qualitativo, apoiado na abordagem da ARC, volta-se à classificação e à descrição das condições de emergência relativas às estruturas das interações observadas, de acordo com as categorias de análise adotadas.

Em uma breve explanação, a ARS consiste em um método alicerçado em três matrizes: a) a da teoria dos grafos; b) a da teoria estatística/probabilística; c) a das análises algébricas (Souza; Quandt, 2008). Conforme apontam Stanley Wasserman e Katherine Faust (1994:5), pode-se entender que o escopo da ARS envolve a combinação entre duas abordagens: a) a composição e a descrição formal da estrutura de uma rede; b) o teste e a avaliação de conceitos e teorias através da modelação de estruturas e de processos relacionais.

Os elementos de identificação fundamentais da ARS são os nós (atores) e as arestas (conexões). Para a realização da análise, os nós e as arestas são ilustradas no modelo de um grafo de redes sociais. Em um grafo é possível definir, por exemplo, as posições dos nós e das arestas conforme o número de vezes em que um se mostrou estar associado a outro, ou seja, de acordo com os seus vínculos formados em uma rede. Esse procedimento geralmente é aplicado para identificar quais agrupamentos de nós (clusters) são centrais ou periféricos, bem como para verificar possíveis "fechamentos" ou "buracos" estruturais emergentes em uma rede (Recuero, 2017). Assim, a análise das redes sociais é efetuada a partir da utilização de dois tipos de métricas: as métricas de nó e as métricas de rede. Entende-se que ambas as métricas são fundamentais para que se possa compreender e/ou descrever o objeto que se busca observar através de um grafo. Nesse sentido, destaca-se abaixo as métricas do grau de entrada (de nó) e a da modularidade (de rede), as quais pretende-se utilizar no procedimento de análise:

A. Métrica da Modularidade: calcula, por meio de um algoritmo (Blondel et al., 2008), índices de coassociações entre os nós de uma rede, de modo a definir agrupamentos formados entre os nós de maior adjacência, bem como as suas respectivas posições no grafo;

B. Métrica do grau de entrada: define a área dos nós de acordo com a sua proeminência perante a totalidade da rede na rede. No caso de uma análise de interações no Twitter, o tamanho de um nó é referente ao número de menções e de retweets recebidos. 
Por sua vez, a ARC encontra-se fundamentada em uma epistemologia sistêmicoconstrutivista, própria da sociocibernética. Essencialmente, a diferença em relação à abordagem da ARS se dá, essencialmente, pelos pressupostos assumidos na compreensão sobre o que forma a comunicação na sociedade. Na medida em que a ARS adere a uma visão estruturalista, focada nas causalidades e nas intencionalidades identificadas nos atores de uma rede, a ARC intenciona observar as redes de interação com base nas noções de relacionalidade, de indeterminação, de contingência e, portanto, de complexidade (Fuhse, 2015b; White, 2007).

Os aportes de investigação da ARC voltam-se a observar a construção social de significados, de símbolos e de conhecimentos, efetuados durante o processo comunicações e interações na sociedade. Essa abordagem favorece a produção de pesquisas intencionadas a identificar e diferenciar as variações semânticas sofridas por conhecimentos em diferentes contextos sociais e/ou temporais (Fuhse, 2015a). Nesse sentido, as contribuições da ARC situamse no sentido de propiciar fundamentos teórico-epistemológicos para a observação e descrição de um complexo de interações emergentes, com foco no apontamento das diferenças e/ou variações apresentadas, seja em relação aos nós e/ou agrupamentos relacionais observados ou entre como, longitudinalmente, os elementos inicialmente observados em uma rede modificaram-se ao longo do tempo.

Os aportes articulados em nossa proposta de uma Análise Sociocibernética de Redes Sociais, conforme o exposto, ancoram-se nas técnicas da ARS a partir de aportes teóricoepistemológicos distintos, vinculados a uma abordagem voltada à complexidade da comunicação. A intenção é, portanto, observar as interações estruturadas em redes sob um modelo voltado à definição de condições/características de emergência, e não às supostas motivações subjetivas de cada ator interagente (Giglietto et al., 2016).

Assim, em diferença quanto aos elementos que compõem as estruturas de redes sociais segundo o modelo usual da ARS, propomos as seguintes especificidades:

A. Os nós de uma rede representam palavras/conceitos imputados no social, advindos de interações, as quais emergem a partir da seleção de códigos;

B. As arestas consistem nas interações desenvolvidas entre os nós, sendo os elementos responsáveis por atribuir, de modo relacional e precário, significado às palavras/conceitos que os nós representam;

C. A formação de clusters em uma estrutura de rede ocorre através do agrupamento de interações cujas expectativas mostraram-se contingentemente redundantes; 


\section{Delimitação do objeto de conhecimento}

A delimitação do objeto de conhecimento envolve o estabelecimento de três contextos temporais distintos para tornar o procedimento de análise operacionalizável. Essa medida faz-se necessária, pois uma vez que o objeto (significados) se trata de algo abstrato e intangível observado apenas na forma de "rastros" de interações digitais (Freelon, 2014) —, é fundamental que seja adotada uma contextualização temporal de referência, de modo a identificar especificamente qual é a "apreensão" daquilo que se pretende analisar. Consoante a isso, a intenção articulada nesta proposta envolve um procedimento longitudinal: identificar as modificações atinentes ao objeto no decurso do tempo, na medida em que interações sociais podem constituir dados contingentes e variáveis.

É a partir dessa perspectiva que se intenciona investigar o objeto de análise, focando-se nas diferenças de sentido responsáveis por formar os significados atribuídos ao evento da “facada” em Jair Bolsonaro no Twitter em diferentes lapsos temporais, quais sejam:

$1^{\text {a) }}$ 06/09/2018: a data na qual ocorreu o atentado da facada em Jair Bolsonaro;

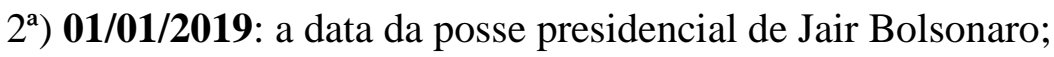

$3^{\text {a) }}$ 28/01/2019 a 30/01/2019: o período no qual Jair Bolsonaro esteve hospitalizado na UTI do hospital Albert Einstein, na cidade de São Paulo, para a retirada de uma bolsa de colostomia;

Os três lapsos temporais utilizados para a análise do objeto foram definidos com base em acontecimentos notórios no contexto sociopolítico brasileiro, diretamente ligados à imagem de Jair Bolsonaro. Diante disso, os três lapsos compreendem, além do próprio dia em que ocorreu o atentado, dois outros períodos temporais sucedidos posteriormente.

A escolha por lapsos temporais atinentes a eventos importantes no cenário sociopolítico do país foi motivada em razão de que, durante aqueles períodos, houve uma tendência de intensificação das interações sociais na internet. De modo geral, eventos notórios na sociedade podem ser vistos como oportunidades para a rememoração de acontecimentos ou mesmo para o levantamento de determinadas pautas sociais ou disputas narrativas na política. Em razão disso, uma vez que objeto analisado está vinculado ao ambiente interacional no Twitter, a escolha por analisá-lo em datas relevantes no contexto sociopolítico também favorece a coleta de uma amostra substancial de dados pelo pesquisador. 
Diante disso, considerada a delimitação da análise a três lapsos temporais específicos, apresenta-se, no quadro abaixo, as informações, de forma mais específica, referentes à seleção dos dados coletados:

Tabela 1: Momentos das coletas de dados no Twitter

\begin{tabular}{|c|c|c|c|c|}
\hline Evento & Data & $\begin{array}{l}\text { Horários de } \\
\text { emissão tweets }\end{array}$ & $\begin{array}{l}\text { Horário das } \\
\text { coletas }\end{array}$ & $\begin{array}{l}\text { Número de } \\
\text { tweets }\end{array}$ \\
\hline $\begin{array}{l}\text { Dia da "facada" } \\
\text { em Jair Bolsonaro }\end{array}$ & 06/09/2018 & $\begin{array}{c}\text { das 17:04 às } \\
\text { 18:04 de } \\
06 / 09 / 2018\end{array}$ & $\begin{array}{c}\text { às } 17: 25 \text { do dia } \\
06 / 09 / 2018\end{array}$ & 23.555 tweets \\
\hline $\begin{array}{l}\text { Dia da posse } \\
\text { presidencial de } \\
\text { Jair Bolsonaro }\end{array}$ & 01/01/2019 & $\begin{array}{c}\text { da } 00: 07 \text { às } 20: 23 \\
\text { de } 01 / 01 / 2019\end{array}$ & $\begin{array}{c}\text { às 14:50; } 15: 34 ; \\
\text { 16:10; } 16: 40 \\
\text { 18:20; do dia } \\
\text { 01/01/2019 }\end{array}$ & 4.726 tweets \\
\hline $\begin{array}{l}\text { Período de } \\
\text { internação de Jair } \\
\text { Bolsonaro na UTI }\end{array}$ & $\begin{array}{c}28 / 01 / 2019 a \\
30 / 01 / 2019\end{array}$ & $\begin{array}{l}\text { da } 00: 03 \text { de } 28 / 01 \\
\text { às } 19: 33 \text { de } 30 / 01\end{array}$ & $\begin{array}{l}\text { desempenhou-se } \\
10 \text { coletas em dias } \\
\text { e horários } \\
\text { distintos }^{1}\end{array}$ & 13.132 tweets \\
\hline
\end{tabular}

Fonte: elaborada pelo autor.

Frente à constituição e à delimitação empírica do objeto desta pesquisa, expõe-se, no subitem a seguir, a metodologia utilizada para a abordagem dos dados.

\section{Matriz analítica da pesquisa: coleta, tratamento e análise dos dados}

Apresentados os aportes atinentes à composição da pesquisa empírica, bem como a constituição do objeto analisado para a abordagem dos dados, expõe-se, a seguir, as etapas utilizadas para a coleta, classificação, organização e análise dos dados.

Utilizou-se quatro diferentes softwares para a operacionalização do procedimento de conhecimento do nosso objeto empírico, relacionado à "facada" em Jair Bolsonaro, os quais serão elencados a seguir, de acordo com a respectiva função desempenhada:

1. NodeXL $L^{2}$ : coleta de dados no Twitter;

2. Notepad $++^{3}$ : conversão e compactação dos tweets coletados para arquivo de texto;

\footnotetext{
${ }^{1}$ Desempenhou-se as coletas nos seguintes dias e horários: 1 ) no dia 28/01: às 09:09, às 09:10, às 14:30, às 15:20, às 18:00 e às 19:02; 2) no dia 29/01: às 08:40; 3 ) no dia 30/01: às 14:30 e às 17:35.

${ }^{2}$ NodeXL: https://nodexl.com/

${ }^{3}$ Notepad++: https://notepad-plus-plus.org/download/v7.6.2.html
} 
3. Textometrica ${ }^{4}$ : filtragem de palavras e cálculo dos graus de coocorrência entre os termos mencionados nos tweets coletados;

4. Gephi ${ }^{5}$ : ilustração dos grafos representativos das estruturas das redes, mediante a aplicação das métricas de análise;

A coleta dos tweets foi desempenhada com o auxílio do software NodeXL. Trata-se de uma aplicação para o programa Microsoft Excel, destinada a coletar e organizar dados oriundos de plataformas de mídias digitais. No caso do Twitter, o NodeXL obtém acesso à API da plataforma, capacitando-se para obter, através da seleção de uma palavra-chave ou hashtag, até 18.000 (dezoito mil) tweets por coleta, na versão "Pro" do programa — utilizada para este artigo. O procedimento de coleta por esse software baseia-se no mesmo princípio, característico das ferramentas de busca na internet, em que os resultados são gerados a partir de palavras-chave específicas. Assim, para a finalidade desta pesquisa, selecionou-se a palavra "facada" como referência para a coleta de tweets.

Adicionalmente, após a coleta dos dados, transcreveu-se o conteúdo dos tweets, os quais permanecem listados na tabela "Q" da planilha do NodeXL, para um arquivo de texto do programa Notepad++. Esse software permite que os espaços gerados no momento da transcrição, entre os conteúdos de um tweet e outro, sejam reduzidos ao se substituir todos os caracteres representados pela sigla "In" (que indica o "espaço" gerado da barra de espaço do teclado) para o símbolo “|”. Após isto, converte-se o arquivo para o formato “.txt”, sob a codificação "-UTF 8", de modo a permitir o processamento do conteúdo dos tweets pelo programa Textometrica.

Nessa etapa, iniciam-se os procedimentos metodológicos de caráter qualitativo. Primeiramente, adiciona-se o arquivo com o conteúdo dos tweets gerado pelo Notepad ++ ao botão "escolher arquivo", disponível no site do programa Textometrica: $<$ http://textometrica.humlab.umu.se/>. Essa aplicação é utilizada para quatro finalidades:

1. Emprego do recurso de "stopwords", para filtrar manualmente as palavras obtidas nos tweets, em que foram excluídos termos isoladamente "neutros", como advérbios, conjunções, preposições e pronomes;

2. Seleção manual das principais palavras/conceitos, conforme a frequência de uso dos termos, a serem utilizados para a construção da análise;

3. Junção entre os valores de palavras significativamente similares, como "armas" e "armamento", para uma mesma unidade conceitual (nó);

\footnotetext{
${ }^{4}$ Textometrica: http://textometrica.humlab.umu.se/

${ }^{5}$ Gephi: https://gephi.org/
} 
4. Cálculo dos graus de coocorrência entre as palavras contidas nos tweets coletados. Após efetuados os quatro passos descritos, o Textometrica gera o resultado em um arquivo no formato ".net" (NET Graph File), o qual é compatível com softwares de formação e visualização de grafos, como o Gephi;

Por fim, o procedimento efetuado no Gephi envolve duas fases, quais sejam: 1) na primeira, calcula-se o grau de modularidade da estrutura da rede através do algoritmo "Force Atlas", definindo os clusters presentes nas redes conforme as suas grupalidades (Blondel et al., 2008); 2); na segunda, calcula-se a métrica de grau de entrada das palavras presentes na estrutura da rede ou, por outras palavras, o número de conexões que cada termo recebeu conforme apontam os tweets coletados. Assim, torna-se possível que cada nó - representado por uma esfera - seja ilustrado proporcionalmente à sua frequência de uso pelos interagentes da rede.

Após a organização dos dados na forma de estruturas de redes, procede-se a análise dos dados conforme as categorias de análise elencadas. Para a aplicação dessas categorias, serão expostos os tweets de maior representação (retweets), que mencionam os principais termos responsáveis pela formação de cada cluster. O conteúdo dos tweets, nesse caso, embasará conjuntamente às posições dos clusters nas redes - a aplicação dos códigos binários, adotados para a classificação dos pressupostos inerentes à construção dos significados relativos ao objeto desta pesquisa (conforme se descreverá no próximo subitem).

$\mathrm{Na}$ figura abaixo (Figura 1), ilustra-se os passos adotados no procedimento de operacionalização dos dados:

Figura 1: Operacionalização dos dados

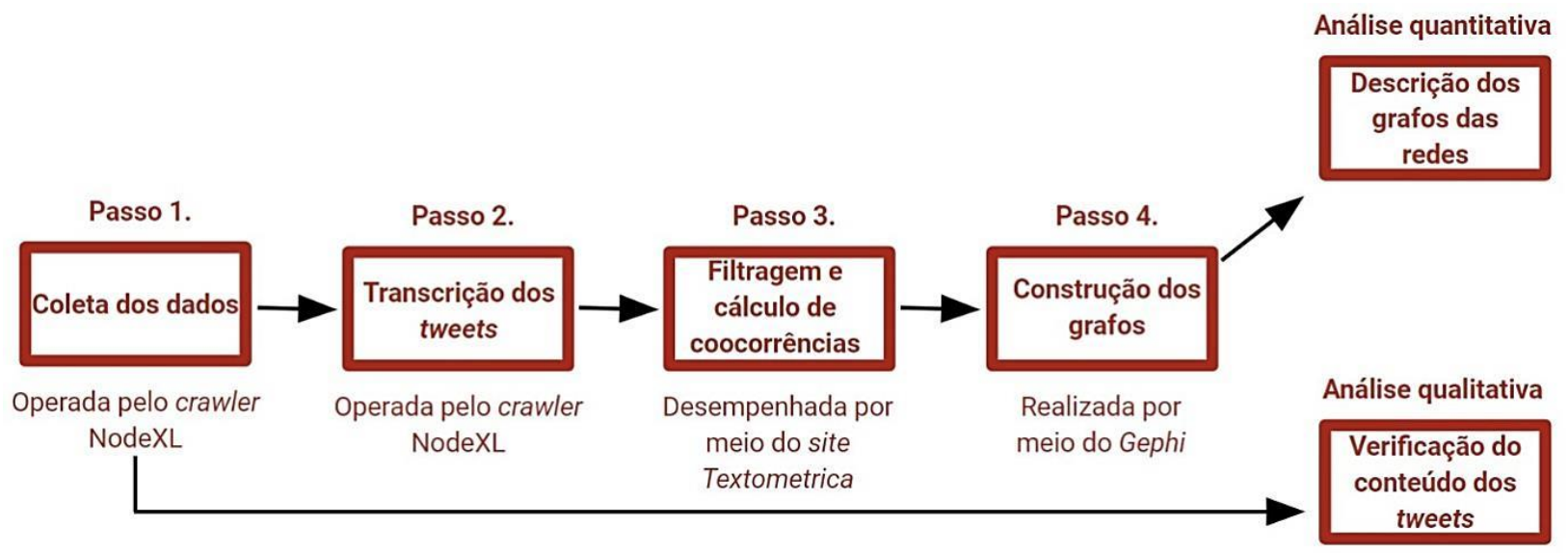

Fonte: elaborado pelo autor.

Finalmente, conforme os itens elencados, o procedimento de análise qualitativa no método proposto é focado na descrição do processo comunicativo produção de significados no Twitter em relação à facada, através da articulação com três categorias de análise. Tais categorias 
são propostas com a intenção de identificar os pressupostos de emergência identificados nas variações semânticas observadas nas redes ilustradas pelos grafos, relativas aos três lapsos temporais pré-definidos. Assim, as categorias de análise, aplicadas nesta metodologia, são articuladas na forma de códigos binários, com base em distinções de orientação luhmanniana (Leydesdorff, 2010):

Tabela 2: Categorias de análise

\begin{tabular}{|l|l|}
\hline \multicolumn{1}{|c|}{ Categoria de Análise } & \multicolumn{1}{c|}{ Codificação } \\
\hline Tipo de localização & núcleo / periferia \\
\hline Tipo de expectativa & cognitiva / normativa \\
\hline Binaridade do código & verdade / não-verdade; favorável / não-favorável; indeterminado \\
\hline
\end{tabular}

Fonte: elaborado pelo autor

As categorias elencadas acima seguem às seguintes determinações:

- Tipo de localização: trata da binaridade núcleo/periferia, a qual se define de acordo com o posicionamento de um nó em uma rede. Essa forma de diferenciação pode existir a partir da constituição de um núcleo central, circundado por unidades periféricas ou diversos núcleos em interação (Luhmann, 2006:530). Geralmente, o núcleo é composto pela "essência" da rede, abrangendo os nós de maior estabilidade e interconexão com os demais, enquanto os nós presentes na periferia tendem a emergir como visões alternativas, precárias e contingentes, em relação ao significado do evento gerador da rede (Fuchs, 2017).

- Tipo de expectativa: refere-se ao modo de observação operacionalizado em um nó na rede. Uma expectativa cognitiva consiste em um modo de observar baseado em fatos, enquanto uma expectativa normativa fundamenta-se em valores (Fuchs, 2001). Assim, um tipo de expectativa cognitiva compreende que o mundo pode ser diferente daquilo que um observador pressupõe, possibilitando o aprendizado, enquanto uma expectativa de tipo normativo possui caráter "contrafático", em resistência à possibilidade de frustração daqueles sentidos pré-construídos (Fuchs, 2017; Luhmann, 2006).

- Binaridade do código: consiste no predicado funcional operado pelo "sistema observador" para estabelecer distinção. Em razão disso, a binaridade do código fundamenta-se no tipo de distinção que um determinado conjunto de nós (clusters) opera. Assim, os códigos não são estruturas estáticas, mas observações variáveis, desenvolvidas segundo a lógica complexa de seleção de sentidos, referencialmente ao que está sendo comunicado nas interações (Fuchs, 2001; Leydesdorff, 2018);

O procedimento qualitativo de imputação das categorias de análise referidas ocorre após a composição de estruturas de redes, isto é, após a efetuação de todas as etapas do procedimento quantitativo de coleta, seleção e classificação dos dados. Consoante a isso, investiga-se o objeto 
de conhecimento a partir da descrição dos seguintes elementos heurísticos: 1) a estrutura analítica da rede; 2) a relacionalidade entre os clusters da rede; 3) as expectativas semânticas operacionalizadas pelos clusters da rede; 4) as características pelas quais se desenvolveram as interações no Twitter (princípios de ordem), conforme as possibilidades de investigação incorporadas do método da ARC (Fuhse, 2009).

A seguir (Figura 2), ilustra-se a heurística de pesquisa, bem como as referências empíricas para as quais se aplicam as categorias de análise elencadas:

Figura 2: Matriz analítica da pesquisa e categorias de análise

\section{Matriz analítica da pesquisa}

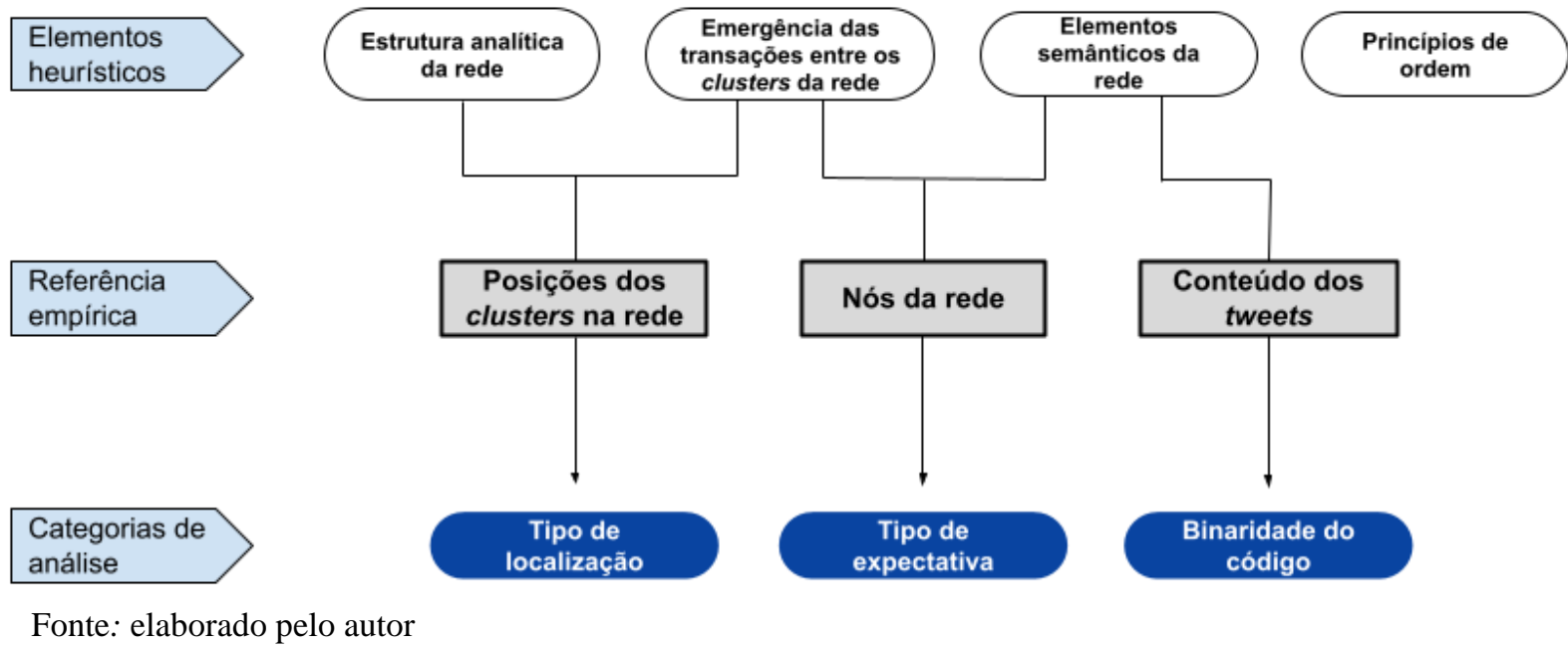

\section{Análise e discussão}

Nos termos da Análise Sociocibernética de Redes Sociais proposta, apresenta-se a seguir os resultados e a discussão desenvolvida relativa aos significados da facada em Jair Bolsonaro. Conforme o exposto a seguir, a análise e a discussão está segmentada conforme a delimitação do objeto de conhecimento em três lapsos temporais.

\section{O dia da "facada"}

O primeiro lapso temporal analisado corresponde às 23.555 interações (tweets) no Twitter em momentos após a ocorrência da "facada" em Jair Bolsonaro, no dia 06/09/2018 (seis de novembro de dois mil e dezoito), a partir das 17h04min (cinco horas e quatro minutos). Identifica-se, conforme exposto no grafo (Figura 3) e na tabela dos conceitos de maior 
frequência (Tabela 3) a seguir, a formação de quatro clusters, constituídos, cada qual, sob pressupostos de observação e perspectivas semânticas específicas:

Figura 3: Rede dos conceitos atribuídos à "facada" no dia do evento

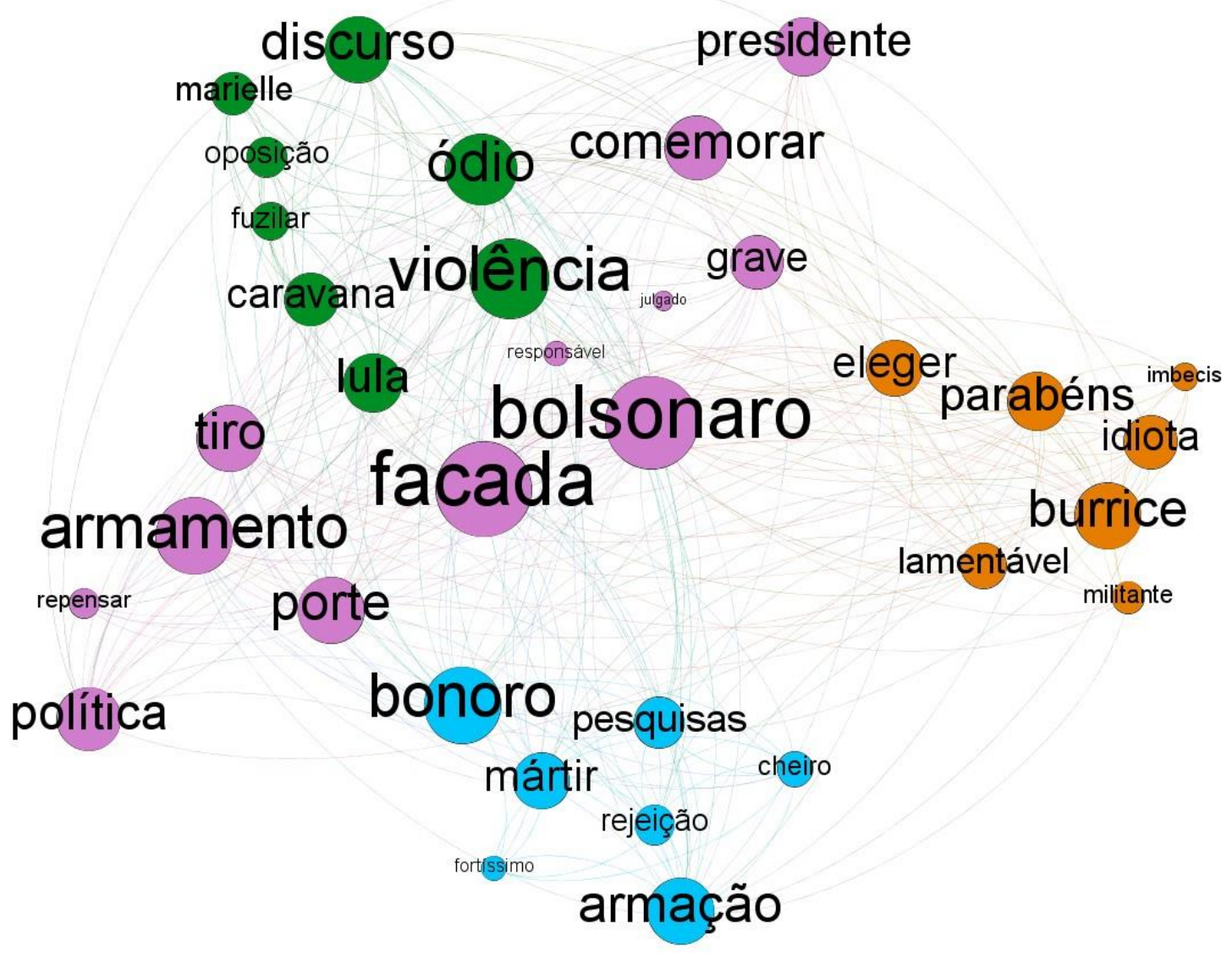

Fonte: elaborada pelo autor.

Tabela 3: Frequência de conceitos — Dia da "Facada"

\begin{tabular}{|l|l|l|}
\hline \multicolumn{1}{|c|}{ Cluster } & \multicolumn{1}{|c|}{ Conceito } & Frequência \\
\hline \multirow{4}{*}{ Rosa } & armamento & 1720 \\
\cline { 2 - 4 } & bolsonaro & 10684 \\
\cline { 2 - 3 } & comemorar & 1221 \\
\cline { 2 - 3 } & facada & 20134 \\
\cline { 2 - 3 } & grave & 696 \\
\cline { 2 - 3 } & julgado & 641 \\
\cline { 2 - 3 } & porte & 1568 \\
\cline { 2 - 3 } & política & 892 \\
\hline
\end{tabular}




\begin{tabular}{|c|c|c|}
\hline & presidente & 870 \\
\hline & repensar & 1324 \\
\hline & responsável & 669 \\
\hline & tiro & 1849 \\
\hline \multirow[t]{8}{*}{ Verde } & caravana & 1099 \\
\hline & discurso & 872 \\
\hline & fuzilar & 566 \\
\hline & lula & 1207 \\
\hline & marielle & 524 \\
\hline & ódio & 1612 \\
\hline & oposição & 509 \\
\hline & violência & 1652 \\
\hline \multirow[t]{7}{*}{ Laranja } & burrice & 1475 \\
\hline & eleger & 814 \\
\hline & imbecis & 774 \\
\hline & idiota & 890 \\
\hline & lamentável & 576 \\
\hline & militante & 827 \\
\hline & parabéns & 1520 \\
\hline \multirow[t]{7}{*}{ Azul } & armação & 1424 \\
\hline & bonoro & 1220 \\
\hline & cheiro & 839 \\
\hline & fortíssimo & 828 \\
\hline & mártir & 820 \\
\hline & pesquisas & 836 \\
\hline & rejeição & 962 \\
\hline
\end{tabular}

Fonte: elaborada pelo autor.

Dentre os quatro clusters apresentados no grafo relativo ao Dia da Facada, percebe-se como há um agrupamento situado no centro da rede (rosa), enquanto os demais (verde, laranja e azul) se encontram em localidades periféricas. Isso indica uma emergência de diversos pontos de 
vista, construídos nas interações atinentes ao acontecimento da facada. Tendo isso em vista, as características dos agrupamentos que constituem a rede são descritas do seguinte modo:

A. O cluster em rosa, localizado no centro da rede, abrange diferentes temas remetentes aos possíveis efeitos políticos, jurídicos e sociais gerados pelo evento, sob palavras como: "bolsonaro"; "facada"; "armamento", "comemorar", "grave", "presidente";

B. O cluster em verde, próximo do agrupamento em rosa, direciona o seu ponto de vista aos demais atos de "violência" observados no campo político brasileiro recente, associando a facada a outros casos recentes, utilizando palavras como: "violência"; "lula"; "caravana"; "marielle", "fuzilar", "discurso", "ódio";

C. Em azul, constata-se uma narrativa afastada das demais, representando uma visão que coloca em dúvida a veracidade da facada, relacionando-a à posição de Jair Bolsonaro nas pesquisas, articulando conceitos como: "armação", "cheiro" "mártir", "pesquisas", "rejeição", "fortíssimo", "bonoro";

D. Na cor laranja, identifica-se um cluster isolado, constituído em lástima quanto aos possíveis reflexos positivos que a facada poderia simbolizar para a campanha de Jair Bolsonaro à presidência do Brasil, através de palavras como: "burrice", "idiota", "lamentável”, "parabéns", “eleger”.

A partir das categorias de análise articuladas - anteriormente expostas na "Tabela 2" aplica-se primeiramente, o "tipo de localização", sob o entendimento de que o cluster rosa corresponde ao agrupamento nuclear dessa rede. Além de englobar os nós de maior centralidade, responsáveis por prover sustentação às demais interações ("facada" e "Bolsonaro"), o agrupamento rosa representa uma linha de indeterminação semântica, servindo como ponto de demarcação entre três extremidades: uma na parte superior (cluster verde), uma na parte inferior (cluster azul) e outra localizada à direita (cluster laranja). Diante disso, os agrupamentos em verde, em azul e em laranja formam as unidades periféricas da rede, uma vez que os seus elementos formam, em essência, perspectivas semânticas idiossincráticas, cada qual observando a "facada" de modo relativamente diverso.

Note-se, conforme a figura abaixo (Figura 4), que os tweets de maior repercussão, observados no agrupamento rosa, correspondem a interações incluindo diferentes pontos de vista, não necessariamente convergentes. Amplamente, principais as interações constituídas no agrupamento rosa levantam os seguintes tópicos: a) lamentações e/ou indignações quanto à "gravidade" do evento; b) as possíveis consequências positivas que a facada poderia gerar para a campanha de Jair Bolsonaro; c) comunicações confusas e/ou indecisas em relação ao significado da facada, relacionando-a, inclusive, a outros temas, como o do porte de armas pela população tema frequentemente levantado por Jair Bolsonaro em sua campanha presidencial. A seguir, ilustra-se (Figura 8) os principais tweets remetentes ao cluster rosa: 
Figura 4: Tweets remetentes ao cluster roxo — Dia da Facada

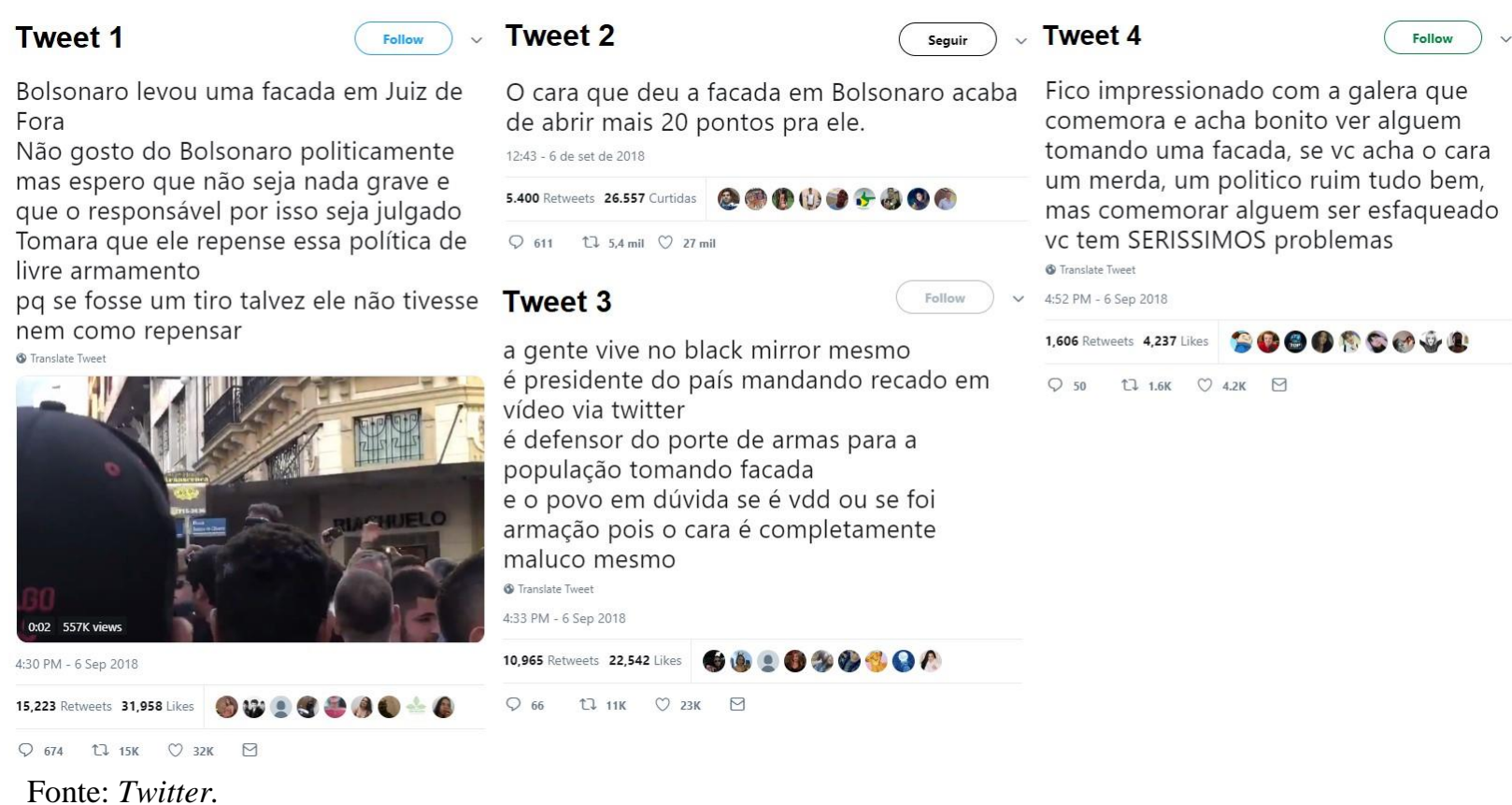

Ao considerar-se a categoria de análise relativa ao "tipo de expectativa", identifica-se que o cluster rosa, diante das características das interações que o constituem, emerge sob expectativas de observação de ordem cognitiva. Isso ocorre em razão de que, apesar de esse agrupamento ser guiado por uma dinâmica de indeterminação, os quatro analisados, expostos na figura acima, não demonstram nenhum tipo de a priori contrafático (Luhmann, 2006). Em contraste, todos os tweets observam a facada, mormente, como um fato, na medida em que não se verifica, nesse agrupamento, interações guiadas por negações, seja em relação à ocorrência do evento ou referentemente a outras interações. Inclusive, consta-se o "Tweet 1 " como um exemplo sobre como a comunicação de um determinado valor, "Não gosto do Bolsonaro politicamente", não infere, necessariamente, que haja uma limitação à autorreflexão por um observador. Assim, de modo geral, o foco do cluster rosa direciona-se às consequências políticas e sociais, potencialmente desencadeadas pelo evento.

Quanto à categoria correspondente à binaridade do código, entende-se que a unidade de interações que representa o cluster rosa possui função binária indeterminada. Argumenta-se que, uma vez que o agrupamento rosa constitui o centro da rede, bem como por representar uma “zona de indeterminação" (Fuchs, 2017), conectada a todos os outros clusters interagentes, não há elementos semânticos suficientemente precisos para que seja possível imputar uma função específica a esse agrupamento de interações. Note-se que, conforme os quatro tweets expostos, o 
centro da rede, embora não se apresente como contrário à veracidade do fato, tampouco exclui possibilidades de questionamentos.

Na periferia da rede do Dia da Facada, encontram-se os agrupamentos verde, azul e laranja. Note-se, diferentemente do cluster rosa, cada um desses agrupamentos encontra-se articulado sob uma perspectiva semântica precisamente delimitada a certas distinções.

Dentre os clusters periféricos, o verde é o que está posicionado de modo mais próximo ao centro da rede, isto é, ao cluster rosa. Essa aproximação decorre de redundâncias compartilhadas entre esses dois agrupamentos, as quais conectam-se através do conceito "violência". No entanto, conforme se observa a seguir (Figura 5), o cluster verde distingue-se ao associar o evento da facada a outros acontecimentos do contexto sociopolítico brasileiro, envolvendo o ataque à caravana de Lula e o assassinato de Marielle.

Figura 5: Tweets remetentes ao cluster verde — Dia da Facada

\section{Tweet 5}

Meses atrás a caravana de Lula foi alvo de tiros. Hj, Bolsonaro levou uma facada. Todos sabem que somos contra as ideias de Bolsonaro. Mas é óbvio que abominamos o uso de violência contra qualquer candidato.

Lamentamos profundamente o ocorrido. Não se combate ódio com ódio.

จ Translate Tweet

4:59 PM - 6 Sep 2018

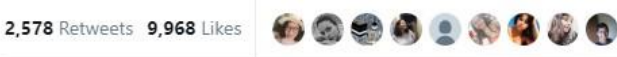

Q $58 \quad$ ᄂ $2.6 \mathrm{~K} \quad \bigcirc_{10 \mathrm{~K}} \quad \square$

Fonte: Twitter.

\section{Tweet 6}

óbvio que ninguém merece levar facada. evidente. porém: está todo mundo muito louco. atiraram na caravana do lula há uns meses; mataram marielle; o próprio agredido tava falando em fuzilar oposição. discurso de ódio não é só discurso, gera ação. e não se relativiza violência.

(6) Translate Tweet

4:34 PM - 6 Sep 2018 from Rio de Janeiro, Brazil

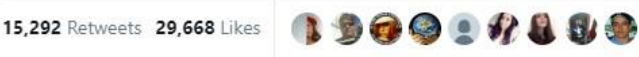

$\bigcirc 234 \quad$ โป $15 \mathrm{~K} \quad \bigcirc \quad 30 \mathrm{~K} \quad \square$

Verifica-se o tipo de expectativa operacionalizada pelo cluster verde como sendo de ordem cognitiva. De modo geral, entende-se que os significados atribuídos por esse agrupamento promovem, "racionalmente", a ideia de que a facada integra uma sequência de atentados contra figuras notórias da política brasileira. Todavia, a distinção observada no cluster verde reside no fato de que, valorativamente, as interações desempenhadas para a emergência desse agrupamento manifestam contrariedade à figura de Jair Bolsonaro, sugerindo que a facada seria uma consequência de "discursos de ódio" proferidos pelo então candidato na sua campanha. Juntamente a isso, a identidade demonstrada pelo cluster verde pode ser vista no rememoramento às figuras de "Lula" e à "Marielle", as quais indicam os pressupostos 
valorativos que indicam, cognitivamente, a perspectiva semântica das interações articuladas nesse agrupamento.

O código funcional operado pelo cluster verde baseia-se na binaridade "verdade/nãoverdade". Isso pode ser verificado, pois, embora as interações expressem contrariedade à figura de Jair Bolsonaro, há o pressuposto da aceitação da facada como um fato, na medida em que o agrupamento verde estabelece comparações a outros eventos os quais assumem como verdadeiros e igualmente ou semelhantemente trágicos, quais sejam, os "tiros na caravana de "Lula" e a "morte de Marielle".

O cluster laranja encontra-se relativamente isolado, situado na periferia à direita da rede. A pauta desse agrupamento está direcionada ao significado da facada para o futuro do pleito eleitoral. Sob os conceitos "burrice”, "lamentável”, "parabéns", “eleger”, as interações que compõem o cluster laranja entendem que o autor da facada, ao invés de prejudicar Jair Bolsonaro, estaria justamente provocando o efeito contrário, aumentando as chances de vitória do candidato na corrida eleitoral para presidente do Brasil. O isolamento desse cluster na rede demonstra a fragilidade dos significados produzidos nas suas interações perante a holística da rede (Fuchs, 2009), indicando que não há proximidade semântica entre os nós que formam o agrupamento laranja e outros - no Twitter, isso ocorre quando a maior parte das interações em um cluster baseia-se em retweets. Abaixo, os tweets de maior repercussão no cluster laranja (Figura 6):

Figura 6: Tweets remetentes ao cluster laranja — Dia da Facada

\section{Tweet 7}

Esfaquearam o Bolsonaro, né.

Parabéns, cidadão que fez isso. Você acaba de eleger ele. Ato duplamente burro: além de uma facada ser lamentável pra qualquer pessoa, ainda tem o efeito contrário do que ele deseja.

$12: 15$ - 6 de set de 2018

16.228 Retweets 43.147 Curtidas

Q 218 นป 16 mil $\bigcirc 43$ mil

Fonte: Twitter.
Seguir

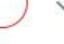

Tweet 8

deram UMA FACADA no bolsonaro, parabéns, vocês acabaram de eleger o cara

$\checkmark$ Translate Tweet

4:19 PM - 6 Sep 2018

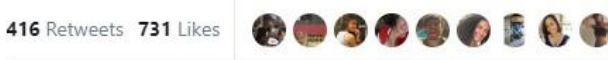

O tipo de expectativa que orienta o cluster laranja é de ordem cognitiva. Note-se, os significados produzidos por esse agrupamento partem do princípio de que a facada efetivamente ocorreu, de modo que as expectativas do agrupamento laranja não oferecem nenhum tipo de 
resistência valorativa às possíveis consequências políticas geradas pela facada. Todavia, de modo particular, a identidade desse cluster é formada, unicamente, em relação às possíveis repercussões negativas que a facada poderia representar para aqueles eleitores contrários à candidatura de Jair Bolsonaro. Isso certifica que mesmo que uma interação possa mostrar-se valorativamente contrária a algo, isso não determina a ocorrência de negações cognitivas/factuais.

A binaridade do cluster trata-se da função "favorável/não-favorável". Observa-se que há uma convergência sedimentada, unicamente, em desaprovação ao autor da facada. Dessa forma, as interações do agrupamento laranja, embora considerem a facada como um ato "lamentável pra qualquer pessoa”, são condensadas, principalmente, ao atribuir ao autor da facada o rótulo de "burro", uma vez que o foco desse cluster tem em vista o possível resultado futuro da eleição.

O último cluster analisado dessa rede, o azul, possui a sua localização isolada na extremidade inferior da rede, em relativa oposição ao agrupamento verde. Isso pode ser observado tanto a partir da relacionalidade oposta entre esses dois clusters na rede, quanto pelos conceitos articulados por ambos. Note-se, o agrupamento azul sintetiza o sentido da facada ao classificar o evento como uma "armação", forjada para transformar Jair Bolsonaro em um "mártir". Na lógica desse cluster, em análise aos tweets expostos a seguir (Figura 7), o ato da facada consistiria numa forma de diminuir a taxa de "rejeição" do candidato perante o eleitorado, conforme os índices apresentados pelas pesquisas eleitorais naquele momento, ou apenas um modo de "comover alguns e ganhar voto".

Figura 7: Tweets remetentes ao cluster azul — Dia da Facada

\section{Tweet 9}

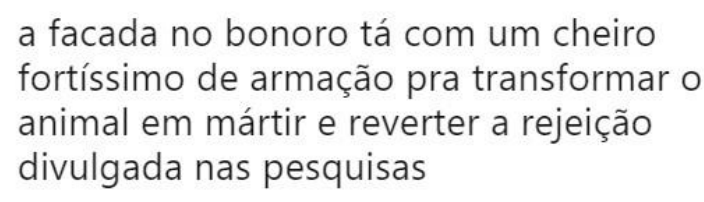

Fonte: Twitter.

\section{Tweet 10}

Follow

"tadinho do Bolsonaro, levou facada, agora vou votar nele."

Pode ser doideira, mas vindo dele, acredito na possibilidade de ter sido armação pra comover alguns e ganhar voto.

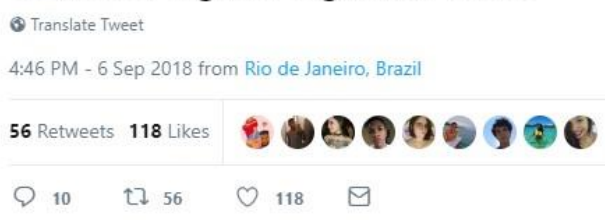


O tipo de expectativa atinente ao agrupamento azul difere-se dos demais observados na rede do "Dia da Facada", sendo de ordem normativa. Em contraste ao observado nos clusters rosa, verde e laranja, as interações desenvolvidas no agrupamento azul operam de modo contrafático, em negação à ocorrência da facada como um evento verídico. Além disso, percebese como o cluster azul distingue-se radicalmente dos demais ao referir-se a Jair Bolsonaro pelo termo "bonoro". Essa peculiaridade interacional pode ser entendida, segundo os termos de Fuchs (2009:347), como uma significação a partir de um “meme", isto é, uma prática cultural intencionada a repelir outras visões semânticas, na medida em que protege a sua própria unidade ao negar os pontos de vista produzidos por outros. Assim, independentemente do mérito quanto à veracidade da facada, verifica-se que os valores inerentes às interações no cluster azul prevalecem sobre o que se apresenta, ao restante da rede, como um fato.

A binaridade do código operacionalizado pelo cluster azul corresponde à distinção "verdade/não-verdade". Oportunamente, constata-se que, em contraste às interações associadas ao agrupamento verde, o cluster azul imputa a distinção de "não-verdade" à facada. Nesse sentido, entende-se que, a despeito de ambos agrupamentos partirem de expectativas valorativas convergentes, ao apresentarem-se como contrários à figura de Jair Bolsonaro, percebe-se como forma-se uma oposição - exposta no grafo, de acordo com a localização dos agrupamentos - em que o cluster verde aceita a facada como verdade, enquanto o azul observa o evento sob uma inferência semântica de negação.

Uma vez analisados todos os clusters que compõem a rede atinente ao "Dia da Facada", exibe-se, na tabela abaixo (Tabela 4), os códigos aplicados aos pressupostos inerentes à emergência de cada cluster:

Tabela 4: Categorias de análise imputadas à rede do Dia da Facada

\begin{tabular}{|l|l|l|l|}
\hline \multicolumn{1}{|c|}{ Cluster } & Tipo de localização & \multicolumn{1}{c|}{ Tipo de expectativa } & \multicolumn{1}{c|}{ Binaridade do código } \\
\hline Rosa & núcleo & cognitiva & Indeterminada \\
\hline Verde & periferia & cognitiva & verdade/não-verdade \\
\hline Azul & periferia & normativa & verdade/não-verdade \\
\hline Laranja & periferia & cognitiva & favorável/não-favorável \\
\hline
\end{tabular}

Fonte: elaborada pelo autor.

De modo geral, a holística da rede de interações constituída no Twitter durante o Dia da Facada apresenta a emergência de uma pluralidade de variações semânticas distintas. Entende-se 
que essa diversidade advém da instabilidade provocada pela ocorrência súbita do evento da facada na sociedade. Nesse caso, a dispersão das interações em quatro agrupamentos denota que a imprevisibilidade, somada à alta complexidade do acontecimento, mostrou-se capaz de gerar uma instabilidade semântica na sociedade. Isso pode ser verificado na medida em que clusters de valores sociopolíticos aparentemente convergentes, como o verde, o azul e o laranja, apesar de se apresentarem contrários à candidatura de Jair Bolsonaro, emergiram sob interações contraditórias e dispersas entre si. Assim, a holística da rede caracteriza-se pela desorganização/indefinição, tipicamente observada em redes de interação ainda "jovens" (Fuchs, 2009).

\section{O Dia da Posse Presidencial}

O segundo lapso temporal investigado engloba os 4.726 tweets constituídos na rede de interações desenvolvida no Twitter durante o dia da posse presidencial de Jair Bolsonaro, na data de 01/01/2019 (primeiro de janeiro de dois mil e dezenove), entre o horário da 00h07min (meianoite e sete) até às $20 \mathrm{~h} 23$ min (vinte e vinte e três). Assim, identifica-se, de acordo com o grafo a seguir (Figura 8), uma nova formação de quatro clusters:

Figura 8: Rede de conceitos atribuídos à facada — Dia da Posse Presidencial

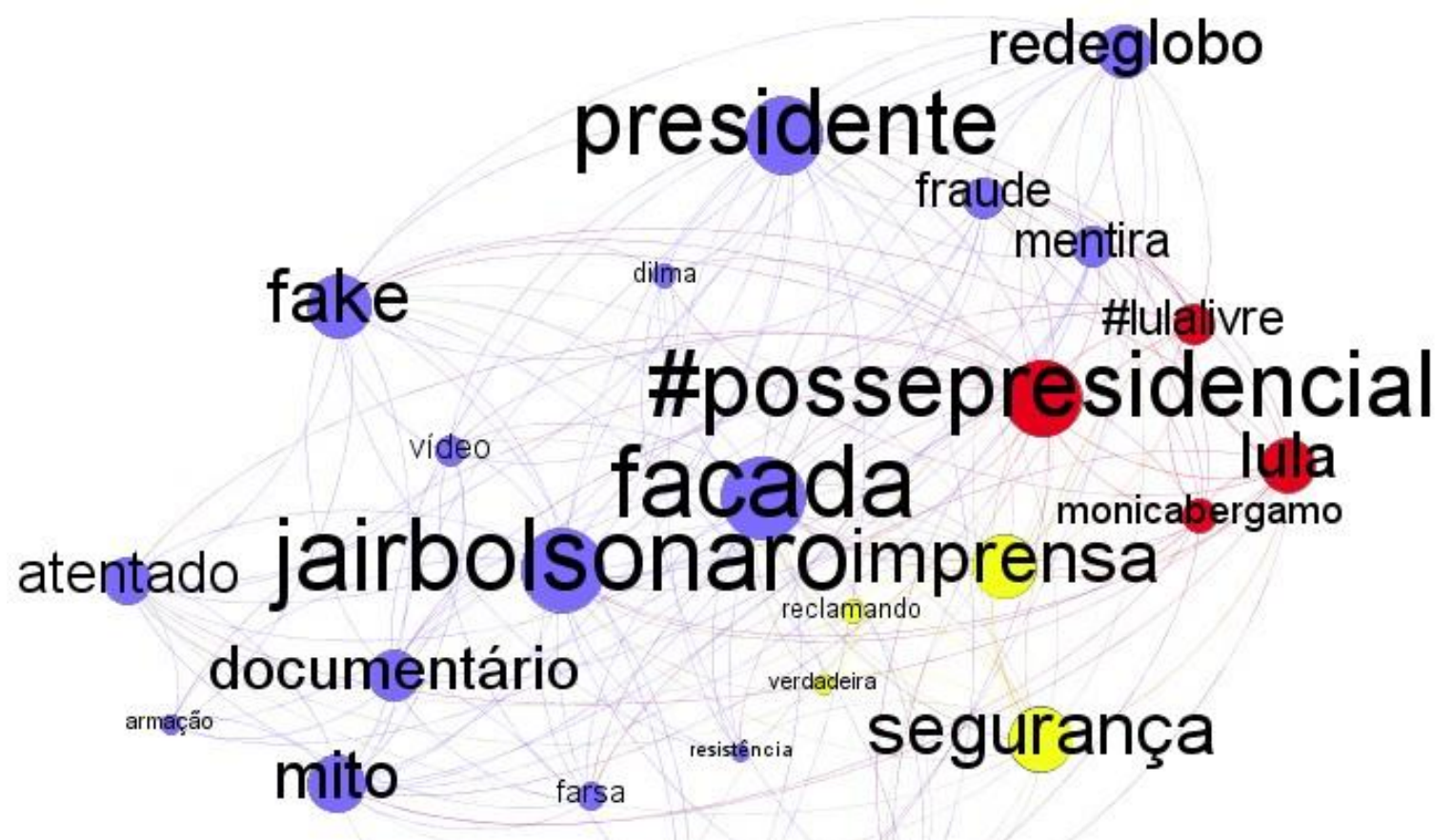

\section{esquerda}

midia

Fonte: elaborada pelo autor. 
Tabela 5: Frequência de conceitos — Dia da Posse Presidencial

\begin{tabular}{|c|c|c|}
\hline Cluster & Conceito & Frequência \\
\hline \multirow[t]{17}{*}{ Roxo } & armação & 49 \\
\hline & atentado & 118 \\
\hline & Dilma & 65 \\
\hline & documentário & 281 \\
\hline & esquerda & 113 \\
\hline & facada & 4562 \\
\hline & fake & 298 \\
\hline & farsa & 197 \\
\hline & fraude & 169 \\
\hline & jairbolsonaro & 852 \\
\hline & mentira & 199 \\
\hline & mídia & 278 \\
\hline & mito & 324 \\
\hline & presidente & 387 \\
\hline & redeglobo & 417 \\
\hline & resistência & 187 \\
\hline & vídeo & 260 \\
\hline \multirow[t]{4}{*}{ Laranja } & imprensa & 725 \\
\hline & reclamando & 672 \\
\hline & segurança & 1113 \\
\hline & verdadeira & 719 \\
\hline \multirow[t]{3}{*}{ Verde } & lula & 524 \\
\hline & monicabergamo & 432 \\
\hline & \#possepresidencial & 822 \\
\hline
\end{tabular}

Fonte: elaborada pelo autor.

Dentre os três clusters expostos no grafo acima, formados pelas interações de 4.726 tweets, atinentes ao Dia da Posse Presidencial, constata-se que há um agrupamento amplo que 
permeia centro, o lado esquerdo e as partes superior e inferior da rede, enquanto existem dois outros clusters menores, relativamente próximos, na parte direita da ilustração do grafo. Identifica-se, diante disso, uma descentralização de significados ainda maior em comparação à rede atinente ao Dia da Facada, formada através das interações entre os seguintes agrupamentos:

A. O cluster em roxo, situado no centro da rede, bem como nas extremidades superior, inferior e à direita, engloba uma pluralidade de perspectivas, centradas em conceitos como: "presidente", "fake", "mito", "redeglobo";

B. O cluster em amarelo, situado na parte inferior da direita, direciona as suas interações especificamente quanto ao trabalho de segurança realizado para a posse de Jair Bolsonaro à presidência do Brasil, sob os termos "segurança" e "imprensa", principalmente;

C. O cluster ilustrado em vermelho representa interações focadas na figura do ex presidente "Lula", traçando comparações entre as posses presidenciais dele e de Jair Bolsonaro, juntamente ao levantamento da pauta do "\#lulalivre";

Em análise à rede do "Dia da Posse Presidencial”, identifica-se que a maior parte da rede é composta por interações dispersas, representadas, em sua maioria, pelo agrupamento roxo. Por estar situado no núcleo da rede, o cluster roxo, sustenta os conceitos que dinamizam a holística das interações ("facada" e "Bolsonaro"). Dessa forma, relacionalmente, os agrupamentos em amarelo e em vermelho correspondem à periferia da rede.

O cluster roxo, apesar de compor o centro da rede, encontra-se definido semanticamente - em sua maior grande parte - sob o pressuposto valorativo de que a facada foi um evento "fake", uma "armação" ou uma "fraude". Conforme se observa nos tweets abaixo (Figura 9), as interações operacionalizadas pelo cluster roxo vinculam-se aos seguintes significados em relação à facada: a) o documentário “A facada no mito", publicado no YouTube no dia 26/12/2018, como a comprovação de que o "atentado" trata-se de uma armação; b) o direcionamento de críticas à 'Rede Globo" e à "mídia tradicional", por supostamente ocultar, nas suas comunicações, o evento da facada. 
Figura 9: Tweets remetentes ao cluster roxo — Dia da Posse Presidencial

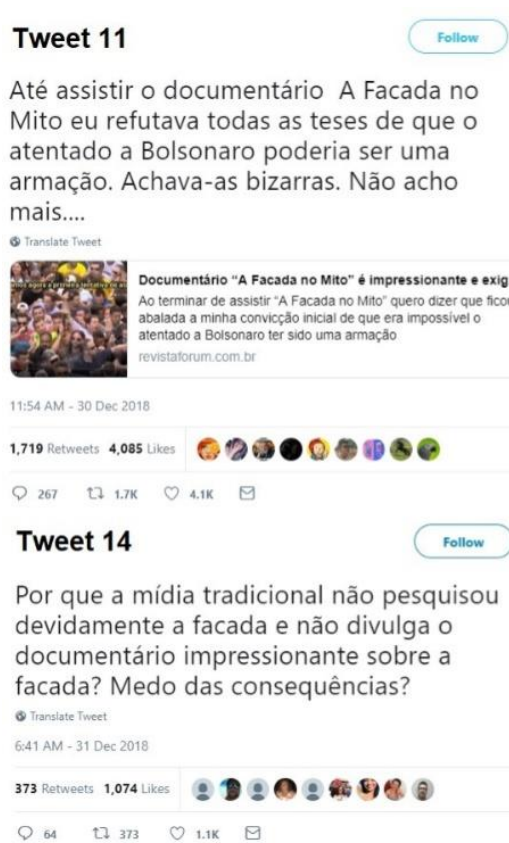

Fonte: Twitter.

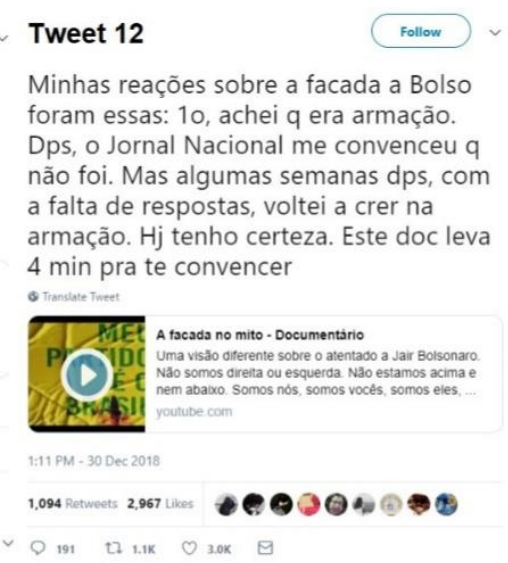

Tweet 13

\#RetrospectivaRENOVA

O portal de notícias "G1", da Rede Globo, fez uma lista com os "15 crimes que abalaram o \#Brasil" em 2018, ignorando completamente o atentado contra o presidente eleito Jair Bolsonaro.

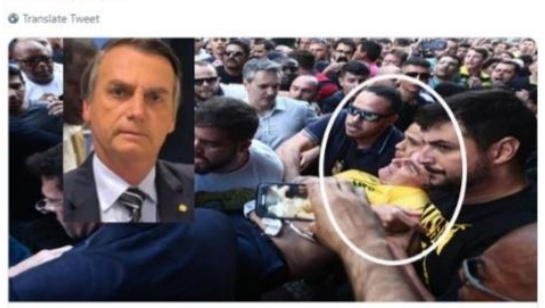

Globo nao cons idera a tacada em Bolsonaro um crime relevante do ano 2018. A Rede Globo optou por nẳo colocar o atentado contra o entăo candidato Jail Bolsonaro na ista dos crimes mals relevantes de 201

6:15 PM - 30 Dec 2018

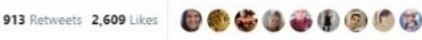

$\bigcirc 280 \quad 27913 \quad \bigcirc_{2.6 K} \quad \boxminus$

No cluster roxo, o tipo de expectativa subjacente às suas interações é indeterminado. Isso ocorre em virtude da diversidade de pontos de vista que integram o centro da rede, representado pelo agrupamento roxo. Pode-se perceber, ao comparar-se os valores dos tweets expostos acima (Figura 9), que há uma mescla entre interações que observam a facada como "fake" (tweets 11, 12 e 14) e, em menor grau, interações que compreendem a facada como um fato pertinente para a história do Brasil (tweet 13).

A binaridade do código operado pelo cluster roxo consiste na distinção "informação/nãoinformação". Identifica-se que as interações desse agrupamento exercem a função comunicativa típica das mídias de massa, ao selecionar o que deve e o que não deve ser comunicado e, a partir disso, emitir - nesse caso, tweetar - uma síntese da realidade, na forma de um conteúdo informativo (Luhmann, 2000). Em razão disso, note-se, conforme a ilustração da Figura 9, que os significados produzidos nos tweets 12, 13 e 14 correspondem a comunicações sobre as observações de veículos de mídia de massa, seja para atribuir uma distinção de ordem negativa a exemplo do "tweet 13" - ou de ordem positiva - caso dos tweets "12" e "14".

O cluster vermelho, situado na periferia da rede, converge as interações desenvolvidas, essencialmente, em referência à figura de "Lula". Tal como se apresentou na rede do "Dia da Facada", a complexidade semântica em torno do conceito "Lula" tende a promover a emergência de agrupamentos específicos, nos quais as sintetizações de sentido, produzidas pelas interações, são estruturadas a partir de pressupostos valorativos quanto à figura de "Lula". No caso da rede atinente à "Posse Presidencial", percebe-se, de acordo com a figura a seguir (Figura 10), a 
produção de diferentes formas de distinção para atribuir sentidos à representação do expresidente:

Figura 10: Tweets remetentes ao cluster vermelho — Dia da Posse Presidencial

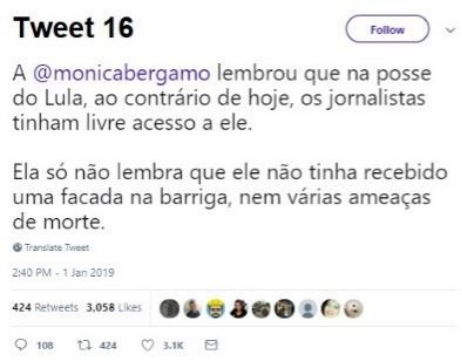

Tweet 16

Tweet 17

Questionamentos: o "jornalão sem rumo"

cobra de Bolsonaro declaração de despesas após facada. E a defesa de Lula, quanto custa e quem paga?

$7011 \mathrm{AM}-30 \mathrm{Dec} 2019$

297 Retweets 1,369 like

Q $93 \quad$ t] $2907 \quad \mathrm{O}_{1.4 \mathrm{~K}} \quad \mathrm{Q}$

\section{Tweet 18}

Verdade. Mas acho que com a farsa da facada exposta e o escândalo dos laranjas, já viram que é uma família de ladrões que tá assumindo então não tem o que comemorar. $\mathrm{O}$ ódio ao Lula vem da vergonha de ter sido manipulado.

S Trasilate Tivet

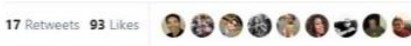

Fonte: Twitter.

Observa-se o tipo de expectativa operacionalizada pelo agrupamento vermelho como indeterminada. Nesse sentido, apesar da diversidade de pressupostos valorativos e cognitivos que constituem esse cluster, verifica-se, nos exemplos dos tweets ilustrados acima (Figura 10), que as interações associadas ao conceito de "Lula" possuem caráter negativo, isto é, contrafático. Aparentemente, o termo "Lula" subjaz frequentemente como um princípio gerador de comparações e controvérsias, tanto por interações valorativamente favoráveis à figura de "Lula", quanto àquelas desfavoráveis.

A binaridade do código funcional do agrupamento vermelho é indeterminada. Particularmente, no que concerne às características desse cluster, percebe-se certa aleatoriedade entre os significados produzidos pelas interações. Isso pode ser verificado na medida em que, ao passo que o tweet "16" interage na rede em referência a acontecimentos concernentes à Posse Presidencial - a partir de comparações entre Jair Bolsonaro e Lula -, os tweets "17" e "18" apenas operam observações alheias às instigações provocadas pelo evento da Posse Presidencial.

O agrupamento amarelo emerge sob a função caracteristicamente periférica de produzir "inovações" (Fuchs, 2009:360) para a holística dos significados que constituem a rede. Em contraste aos clusters roxo e vermelho, esse agrupamento emerge unicamente em atribuição de uma distinção a uma informação anterior, comunicada sobre o esquema de segurança montado para a Posse Presidencial. Assim, em referência às supostas "reclamações" de parte da imprensa presente no evento, o cluster amarelo entende, homogeneamente, que qualquer "excesso" cometido pela equipe de segurança do "Palácio do Planalto" é justificável, visto que Jair Bolsonaro havia sido vitimado pelo atentado da facada, aqui inferida, portanto, como verídica. Na figura abaixo (Figura 11), apresenta-se os tweets que representam o agrupamento amarelo: 
Figura 11: Tweets remetentes ao cluster amarelo — Dia da Posse Presidencial

\section{Tweet 14}

Estou com toda a imprensa aqui na terceira vistoria de segurança desde o CCBB até ao Palácio do Planalto. Alguns jornalistas estão reclamando o "excesso" de segurança. Como sei que a facada foi verdadeira, não me incomodo. Os que reclamam parecem esquecer da facada.

(2) Translate Tweet

10:07 AM - 1 Jan 2019

1,943 Retweets 12,652 Likes $300 \div$

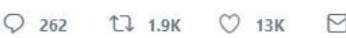

Fonte: Twitter.

\section{Tweet 15}

Follow

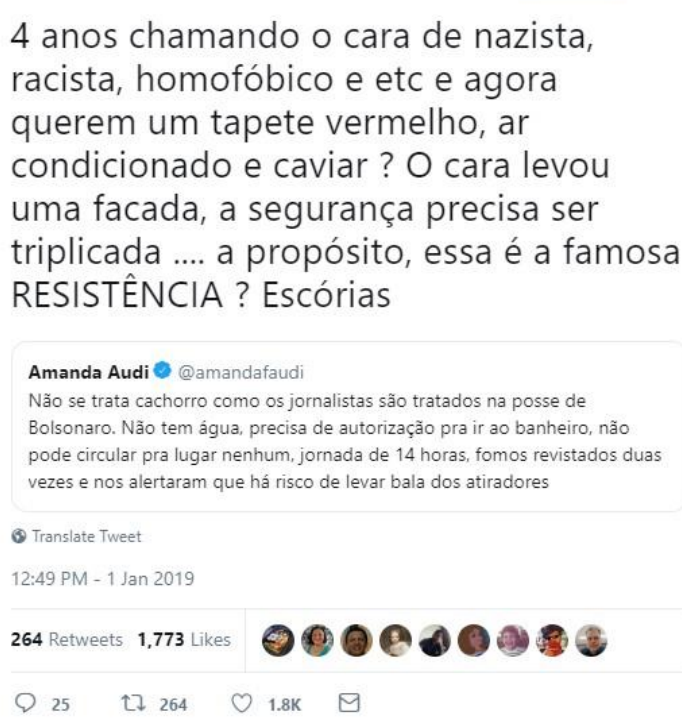

4 anos chamando o cara de nazista, racista, homofóbico e etc e agora querem um tapete vermelho, ar uma facada, a segurança precisa ser triplicada .... a propósito, essa é a famosa RESISTÊNCIA ? Escórias

Constata-se, na análise dos tweets associados ao cluster amarelo, que o tipo de expectativa operacionalizada nesse cluster é de ordem normativa. Isso pode ser verificado, pois há uma negação contrafática em relação às "reclamações" da imprensa quanto às medidas de segurança adotadas para a Posse Presidencial. No exemplo do tweet "14", o pressuposto valorativo atinente à facada como "verdadeira" prevalece diante de qualquer distinção advinda da comunicação de "reclamações" emitidas por jornalistas. No caso do tweet "15", essa indução de valores encontra-se nitidamente perceptível, uma vez que, no agrupamento amarelo, a imprensa passa a ser vista como "escórias", associada a uma suposta "resistência" à figura do presidente eleito.

A binaridade do código funcional, estruturado pelo cluster amarelo, corresponde à distinção "favorável/não favorável". Nesse caso, o sentido atribuído à facada pelo agrupamento amarelo, sob o contexto da Posse Presidencial, é de que a sua veracidade sustenta a rigorosidade da "vistoria" realizada pela equipe de segurança do "Palácio do Planalto". Em razão dessa expectativa, ao produzir distinção à comunicação da imprensa, quanto ao caráter do esquema de segurança montado, o cluster amarelo demonstrou-se eminentemente favorável.

Diante da descrição traçada, exibe-se, a seguir, tabela ilustrativa (Tabela 6) das categorias de análise aos clusters presentes na rede relativa à Posse Presidencial: 
Tabela 6: Categorias de análise imputadas à rede do Dia da Posse Presidencial

\begin{tabular}{|l|l|l|l|}
\hline \multicolumn{1}{|c|}{ Cluster } & Tipo de localização & \multicolumn{1}{c|}{ Tipo de expectativa } & \multicolumn{1}{c|}{ Binaridade do código } \\
\hline Roxo & núcleo & indeterminada & $\begin{array}{l}\text { informação/não- } \\
\text { informação }\end{array}$ \\
\hline Amarelo & periferia & normativa & favorável / não-favorável \\
\hline Vermelho & periferia & normativa & favorável / não-favorável \\
\hline
\end{tabular}

Fonte: elaborada pelo autor.

Na rede de interações constituída cerca de quatro meses após a ocorrência da facada, no Dia da Posse Presidencial de Jair Bolsonaro, percebe-se uma tendência de formação de estabilidade na rede, uma vez que expectativas valorativas convergentes, fundadas na contrariedade à eleição de Jair Bolsonaro, unificaram-se, mesmo que dispersamente, em um mesmo agrupamento de sentidos. Conjuntamente a isso, interações favoráveis à figura do, naquele momento, presidente eleito, emergiram e fortaleceram os seus laços semânticos sob unidades "próprias" (cluster amarelo), distinguindo-se parcialmente do restante da rede, ao promover "exclusões" (Luhmann, 2006:500) aos sentidos comunicados nas interações que compreendiam a facada como uma armação. Sob essa tendência, o cluster vermelho representa conceitos relacionalmente ainda indefinidos perante a holística das interações.

\section{O período da cirurgia}

O terceiro - e último - lapso temporal analisado compreende o período do dia 28/01/2019 (vinte e oito de janeiro de dois mil e dezenove) a 30/01/2019 (trinta de janeiro de dois mil e dezenove), no qual Jair Bolsonaro esteve internado na Unidade de Terapia Intensiva (UTI) do hospital Albert Einstein, em São Paulo, para a retirada da bolsa de colostomia que havia sido acoplada ao seu intestino, como consequência da facada.

Diante disso, analisa-se um total de 13.132 (treze mil cento e trinta e dois) tweets, emitidos a partir das interações desempenhadas no Twitter relativas à facada, durante o período especificado acima. Inicialmente, verifica-se, conforme o grafo a seguir (Figura 12) e a tabela a seguir (Tabela 7), que essa rede se encontra constituída por apenas dois clusters, posicionados em oposição um ao outro - ou seja, de modo polarizado. 
Figura 12: rede de conceitos atribuídos à "facada" no Período de Internação de Jair Bolsonaro

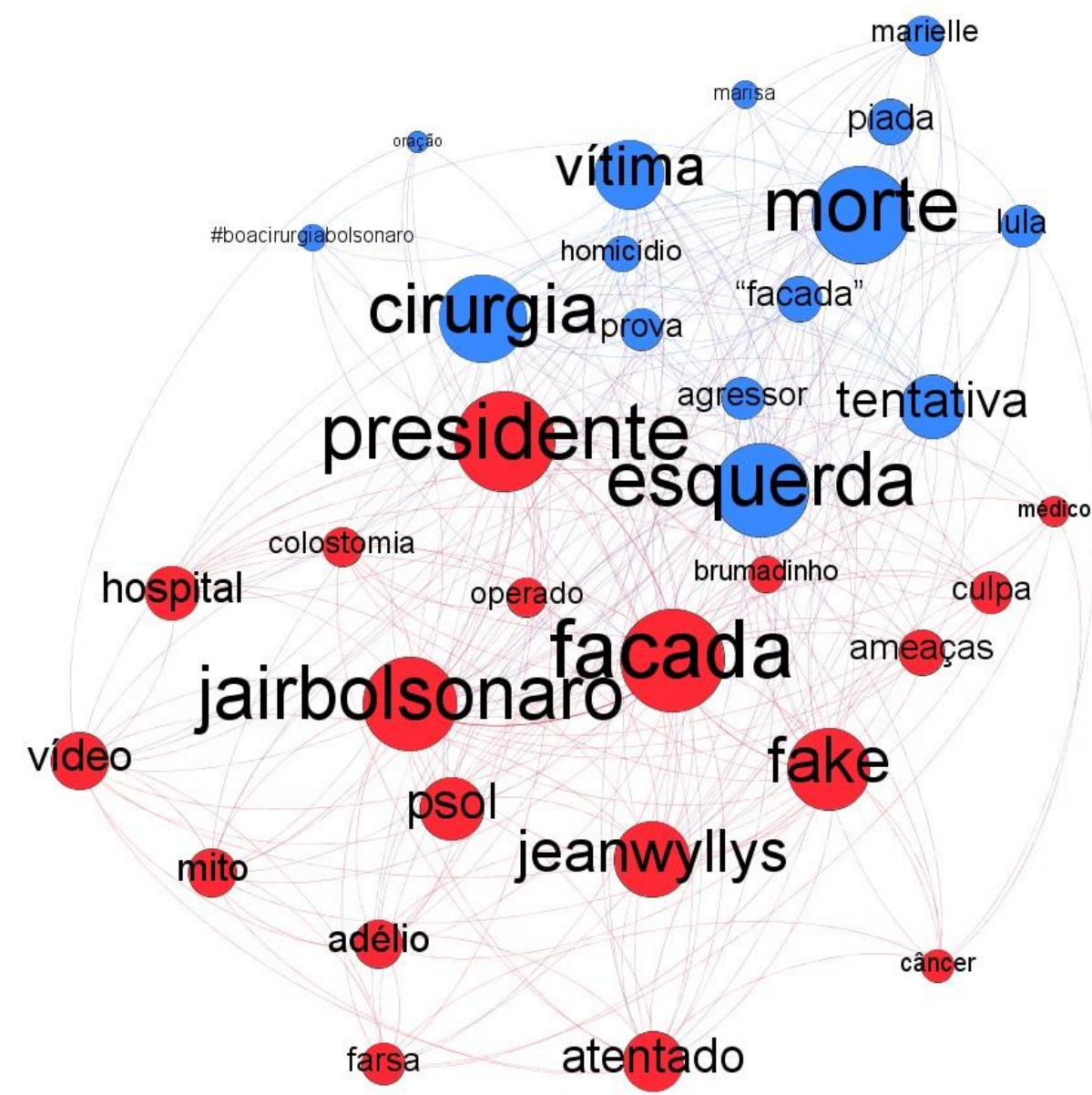

Fonte: Twitter.

Tabela 7: Frequência de conceitos — Dia da Posse Presidencial

\begin{tabular}{|l|l|l|}
\hline \multicolumn{1}{|c|}{ Cluster } & \multicolumn{1}{c|}{ Conceito } & Frequência \\
\hline Vermelho & adélio & 487 \\
\cline { 2 - 4 } & ameaças & 390 \\
\cline { 2 - 4 } & atentado & 291 \\
\cline { 2 - 4 } & brumadinho & 546 \\
\cline { 2 - 4 } & câncer & 113 \\
\cline { 2 - 4 } & colostomia & 238 \\
\cline { 2 - 4 } & culpa & 292 \\
\cline { 2 - 4 } & facada & 12762 \\
\hline & fake & 2406 \\
\hline & farsa & \\
\hline
\end{tabular}




\begin{tabular}{|c|c|c|}
\hline & hospital & 1907 \\
\hline & jairbolsonaro & 2769 \\
\hline & jeanwyllys & 1405 \\
\hline & médico & 177 \\
\hline & mito & 387 \\
\hline & operado & 691 \\
\hline & presidente & 4269 \\
\hline & psol & 926 \\
\hline & vídeo & 279 \\
\hline Azul & agressor & 699 \\
\hline & \#boacirurgiabolsonaro & 580 \\
\hline & cirurgia & 1757 \\
\hline & esquerda & 1981 \\
\hline & homicídio & 693 \\
\hline & lula & 384 \\
\hline & marielle & 259 \\
\hline & marisa & 233 \\
\hline & morte & 1452 \\
\hline & oração & 229 \\
\hline & piada & 706 \\
\hline & prova & 711 \\
\hline & tentativa & 1012 \\
\hline & vítima & 772 \\
\hline & "facada" & 701 \\
\hline
\end{tabular}

Fonte: elaborada pelo autor.

O cluster vermelho, localizado no extremo inferior do grafo, é formado pela aproximação de palavras como "fake", "jeanwyllys", “atentado" e "hospital”. Nesse agrupamento, constrói-se, em referência aos eventos concernentes à operação de Jair Bolsonaro, a narrativa de que o presidente estaria utilizando a facada como justificativa para, ao invés de retirar a bolsa de 
colostomia, "fazer quimioterapia", pois estaria com câncer, segundo as interações associadas ao cluster vermelho.

O cluster azul, situado na parte superior, como se pode constatar, imputa significados à facada, principalmente sob a articulação de conceitos como "tentativa", "homicídio", "vítima", "cirurgia" e "esquerda". A partir disso, nota-se que esse agrupamento, além de observar a facada como um fato verídico, entende que o evento não se tratava de uma mera "facada", mas de uma "tentativa de homicídio" negada pela "esquerda", da qual Jair Bolsonaro seria a "vítima".

A rede de interações correspondente ao período de internação de Jair Bolsonaro demonstra, portanto, a emergência de duas narrativas essencialmente opostas e relacionalmente interdependentes, caracterizando-se, portanto, como polarizadas. Isso indica que não há o estabelecimento de um núcleo semântico, no qual se encontram os conceitos centrais da rede, e a periferia, abrangendo as interações de características alternativas (Fuchs, 2009). Diferentemente disso, entende-se que há a presença de dois núcleos inconciliáveis, em uma dinâmica na qual "existe uma multiplicidade de centros, entre os quais um exerce a hegemonia" (Luhmann, 2006:526). Assim, o cluster vermelho guia-se, valorativamente, pela ideia de que a facada é um "atentado" "fake", enquanto o agrupamento azul se orienta a partir da narrativa de que, ao invés de uma mera facada, houve uma "tentativa" de "matar" Jair Bolsonaro.

Diante disso, apresenta-se os principais tweets associados ao cluster azul (Figura 13):

Figura 13: Tweets remetentes ao cluster azul — Período de Internação de Jair Bolsonaro

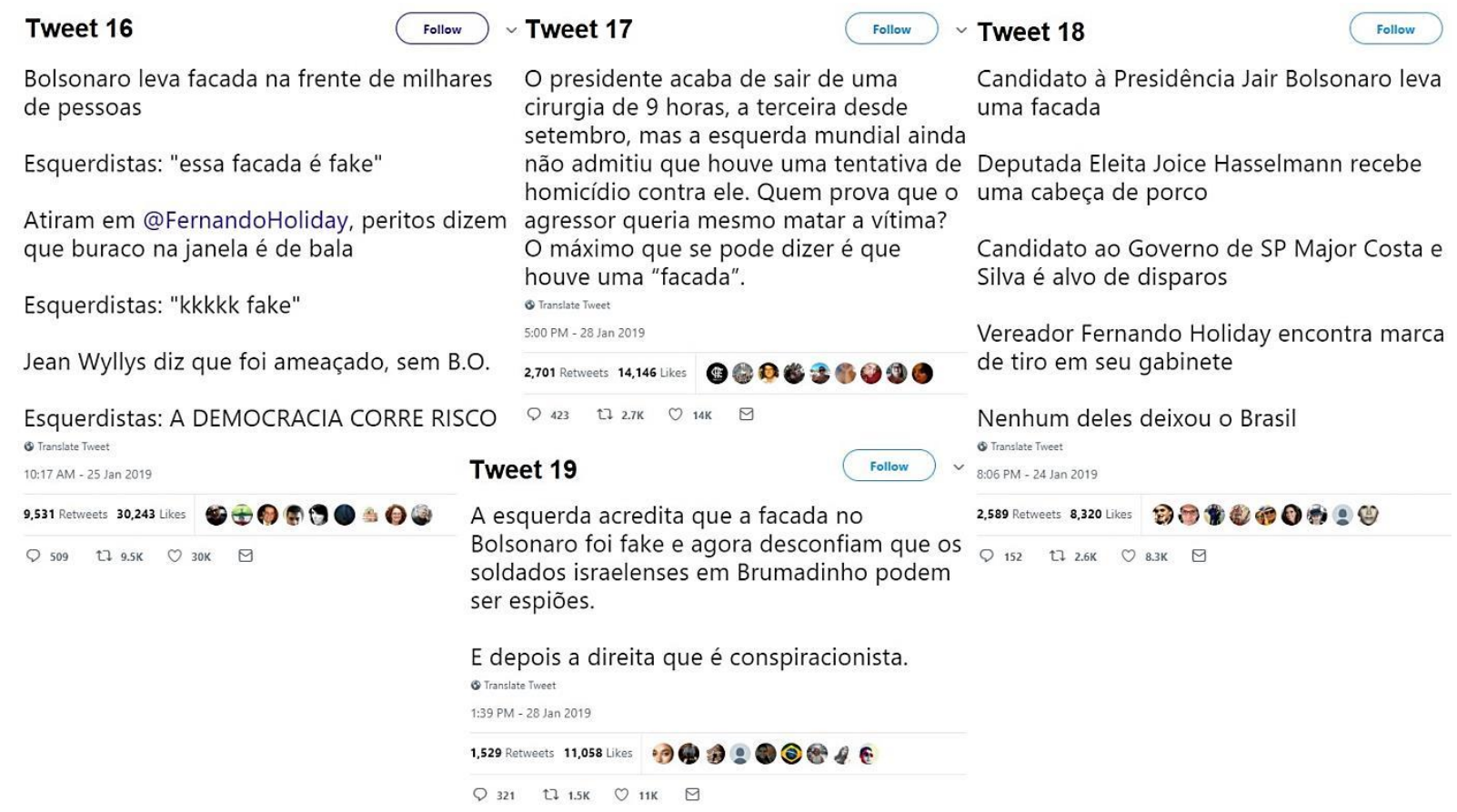

Fonte: Twitter. 
Em análise aos tweets, verifica-se o tipo de expectativa operacionalizada pelo agrupamento azul como de ordem normativa. O indicativo disso reside, sobretudo, na constante negação explícita e implícita ao ponto de vista do outro, neste caso, da "esquerda". Percebe-se, em todas as interações analisadas na figura acima (Figura 13), que os significados produzidos pelo cluster azul partem de expectativas frustradas em relação a comunicações advindas dos “esquerdistas" ou por "aqueles que deixaram o Brasil" - em menção velada à renúncia do exdeputado federal, Jean Wyllys, ao seu cargo no Congresso Nacional, à vista de ameaças que vinha frequentemente recebendo. Isso ocorre, pois, os significados relativos à facada, produzidos pelo agrupamento azul, partem de pressupostos semânticos fundamentalmente valorativos e, portanto, contrafactuais.

A binaridade do código estruturado pelo agrupamento azul corresponde à distinção "verdade/não-verdade". Nesse caso, note-se que a imputação quanto ao que é verdadeiro ou falso sobrevém de negações à verdade do outro - isto é, a partir da elucidação de distinções perante as "conspirações" criadas pela "esquerda". Além disso, as interações presentes no agrupamento azul relembram eventos, tais como os "tiros" no gabinete de "Fernando Holiday", bem como a própria facada, como formas de refutar as comunicações sobrevindas do cluster vermelho. Assim, o agrupamento azul orienta a sua construção de sentidos, essencialmente, em relação às contradições naquilo em que observa sobre o seu lado oposto.

Quanto ao agrupamento vermelho, identifica-se a operacionalização de expectativas de tipo normativo, conforme os tweets expostos a seguir (Figura 14):

Figura 14: Tweets remetentes ao cluster vermelho - Período de Internação de Jair Bolsonaro

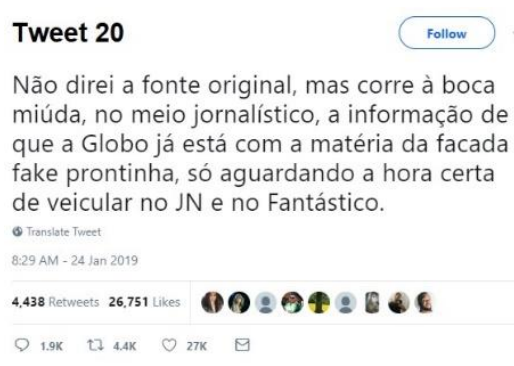

Tweet 23

Existe uma forma das fakenews com a facada amplamente televisionada do Presidente

acabarem: a investigação esclarecer ao Brasil TUDO sobre o episódio.

- Translate Tweet

$5: 31$ PM - 25 Jan 2019

992 Retweets 8,791 likes $\& \& 0000$

(2) $699 \quad$ t2 992 ○ $8.8 \mathrm{KK} \quad \mathrm{Q}$

Fonte: Twitter.

\section{Tweet 21}

O que diferencia os grandes dos pequenos: no dia em que

@jairbolsonaro sofreu uma facada Jean Wyllys prestou solidariedade. Minutos depois de Wyllys informar que deixará o mandato e sairá do país por questão de segurança foi ironizado pelo presidente no Twitter.
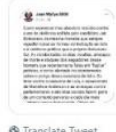

CTransiate Theet
5:52 PM - 24 Jan 2019

3,992 Retweets 11,167 Likes

○ $294 \quad$ t2 $4.0 \mathrm{~K} \quad \mathrm{O}_{11 \mathrm{~K}} \quad \mathrm{Q}$

\section{Tweet 22}

9 horas para tirar uma bolsa de colostomia? 6 qual desculpa darão quando ele estiver fazendo quimioterapia? outra facada? até quando vão continuar mantendo essa farsa?
- Transiste Tweet

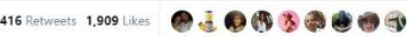


Note-se, da mesma forma que o seu agrupamento oposto, esse cluster orienta o seu modo de produzir sentidos, sobretudo, a partir de negações em relação a uma figura construída sobre o outro. Além disso, verifica-se, conforme o tweet "20", a expectativa de que a narrativa a respeito da facada como um evento "fake" trata-se de uma verdade prestes a ser "esclarecida", mediante a validação operacionalizada por veículos de mídia de massa, como a "Globo". Consoante a isso, identifica-se que o cluster vermelho, igualmente ao seu oposto em azul, observa as suas próprias observações como se fossem pontos de vista hierarquicamente superiores aos demais, construídos sob argumentos racionais e factuais, sendo este o critério responsável que "diferencia os grandes dos pequenos".

A partir da análise dos clusters azul e vermelho, exibe-se, a seguir, a tabela das categorias de análise imputadas aos clusters presentes na rede remetente ao "Período de Internação de Jair Bolsonaro" (Tabela 8):

Tabela 8: Categorias de análise imputadas à rede do Período de Internação de Bolsonaro

\begin{tabular}{|l|l|l|l|}
\hline \multicolumn{1}{|c|}{ Cluster } & Tipo de localização & \multicolumn{1}{c|}{ Tipo de expectativa } & \multicolumn{1}{c|}{ Binaridade do código } \\
\hline Azul & núcleo & normativa & verdade/não-verdade \\
\hline Vermelho & núcleo & normativa & verdade/não-verdade \\
\hline
\end{tabular}

Fonte: elaborada pelo autor.

A polarização constituída na rede das interações sociais desenvolvidas durante a internação de Bolsonaro corrobora com a ideia de que o processo sistêmico de autorreferência observa (seleciona) a complexidade e produz, mediante exclusões, sentidos compatíveis com os seus valores inerentes (Luhmann, 2006). Em razão disso, atribui-se à polarização de perspectivas semânticas em relação à facada como fruto do processo gradual de estabilização de uma rede (Fuchs, 2009), no qual, não por acaso, houve uma sintetização de significados a partir da formação de dois agrupamentos relacionalmente opostos. Todavia, note-se que, nesse caso, ao invés de distinguirem-se perante um centro indeterminado, responsável por sustentar a rede, os dois clusters (azul e vermelho) constituem-se a partir das suas próprias binaridades, isto é, significam-se um em distinção - ou em negação, conforme os preceitos da Teoria do Discurso de Laclau e Mouffe (2015), articulada em um outro trabalho no contexto das Eleições de 2018 (Vinhas; Sainz; Recuero, 2020) - ao outro, sob uma dinâmica essencialmente valorativa. 


\section{Considerações finais}

O presente artigo abordou a construção de sentidos acerca da facada em Jair Bolsonaro, ocorrida durante a campanha eleitoral de 2018 no Brasil, nas interações sociais no Twitter. A partir da combinação entre os aportes computacionais utilizados por métodos de análise de redes sociais na internet e uma abordagem teórico-epistemológica fundamentada na complexidade da comunicação, propôs uma metodologia que se chamou de Análise Sociocibernética de Redes Sociais. Dessa forma, por um enfoque quantitativo, observou-se como se desdobraram as dinâmicas de produção de significados em torno da facada em Jair Bolsonaro, enquanto, qualitativamente, descreveu-se as condições de emergência através das quais se constituíram e se agruparam as diferentes perspectivas (verdades) em relação ao evento.

Identificou-se, através da descrição dos três grafos relativos aos lapsos temporais analisados, como a sintetização - ou, mais precisamente, a exclusão - de sentidos na comunicação estabilizou a complexidade da facada em Jair Bolsonaro a partir da formação de uma polarização política e/ou social no decorrer do tempo. Se, inicialmente, observou-se uma diversidade de pontos de vista ainda em estado incipiente e, portanto, de incerteza em relação ao evento, por outro, na medida em que novas interações desenvolveram-se e atualizaram-se frente a novos acontecimentos no cenário sociopolítico brasileiro, deu-se por construída uma dinâmica de polarização, abrangendo significados opostos em relação à facada, guiados por pressupostos essencialmente valorativos, normativos e, portanto, contrafactuais.

Desse modo, verificou-se no último período analisado que o evento ocorrido, isto é, a facada, diluiu-se em duas verdades relacionalmente antagônicas (opostas), construídas em referência ao desfecho das Eleições de 2018 no Brasil: enquanto um dos agrupamentos sintetizou a facada como um acontecimento forjado para favorecer a eleição de Jair Bolsonaro à presidência do país, o outro reduziu a complexidade do evento a uma tentativa de assassinato, como forma de evitar uma provável eleição do então candidato. De tal forma, os significados produzidos no Twitter em relação à facada formaram duas "verdades" em disputa, estruturadas como narrativas essencialmente opostas e relacionalmente interdependentes - passando a caracterizar o que comumente chama-se de "polarização".

A singularidade buscada neste trabalho se mostra na convergência proposta entre a capacidade computacional de coletar, organizar e analisar automaticamente uma quantidade de dados relativamente grande e o potencial da teoria sociológica de compreender tais dados como indicativos socialmente relevantes acerca de como se compõe a realidade contemporânea. Diante disso, a metodologia desenvolvida, a qual se intitulou Análise Sociocibernética de Redes Sociais, 
permite possibilidades de um acréscimo qualitativo profícuo ao entendimento da dinâmica de produção de significados nas interações em redes sociais, ainda que em uma fase incipiente de elaboração.

Por fim, entende-se que as limitações presentes em nossa proposta podem suscitar o desenvolvimento de trabalhos futuros interessados em explorar as dinâmicas das redes sociais sob lentes construtivistas que envolvam métodos computacionais. Nesse sentido, diante do crescimento recente da Ciência Social Computacional para além de prerrogativas meramente analíticas, mas também em termos de acessibilidade, reprodutibilidade e transparência na pesquisa social, a principal contribuição do presente artigo consta na proposição de uma interlocução entre teoria social e métodos computacionais. Assim, buscou-se estabelecer uma articulação frutífera para a ampliação ou reconfiguração de teorias já consolidadas nas ciências sociais de modo comensurável a paradigmas de pesquisa computacionais.

\section{Referências}

ALMANAGUER-KALIXTO, Patricia Eugenia; GIGLIETTO, Fabio (2019), "Steering the world from where we are: An introduction to the sociocybernetics perspective". Current Sociology, v. 67, n. 4, pp. 479-494 [Consult. 18-12-2021]. Disponível em https://doi.org/10.1177/0011392119837573

ALTMANN, Philipp; PETERS, Robert (2018), "Introduction: Special issue: Complexity and Truth". Journal of Sociocybernetics, v. 15, n. 2, pp. 1-4 [Consult. 18-12-2021]. Disponível em https://papiro.unizar.es/ojs/index.php/rc51-jos/article/view/3286

BAECKER, Dirk (2007), "Communication With Computers, or How Next Society Calls for an Understanding of Temporal Form". Soziale Systeme, v. 13, pp. 409-420 [Consult. 18-12-2021]. Disponível em https://papers.ssrn.com/sol3/papers.cfm?abstract_id=1867443

BASTOS, Marco Toledo (2011), "Public Opinion Revisited: The propagation of opinions in digital networks". Journal of Arab \& Muslim Media Research, v. 4, n. 2-3, pp. 185-201 [Consult. 18-122021]. Disponível em https://doi.org/10.1386/jammr.4.2-3.185_1

BASTOS, Marco Toledo (2014), "Digital notation and spectral meaning". International Journal of Applied Systemic Studies, v. 5, n. 3, pp. 177-189 [Consult. 18-12-2021]. Disponível em https://www.inderscienceonline.com/doi/abs/10.1504/JJASS.2014.064060

BLONDEL, Vincent; GUILLAUME, Jean-Loup; LAMBIOTTE, Renaud; LEFEBVRE, Etienne (2008), "Fast unfolding of communities in large networks". Journal of Statistical Mechanics: Theory and Experiment, v. 10, P1000, pp. 1-12 [Consult. 18-12-2021]. Disponível em https://arxiv.org/abs/0803.0476

CESARINO, Letícia (2021), "Pós-verdade e a crise no Sistema de peritos: uma explicação cibernética". Ilha: Revista de Antropologia, v. 23, n. 1, pp. 73-96 [Consult. 18-12-2021]. Disponível em https://doi.org/10.5007/2175-8034.2021.e75630

FREELON, Deen (2014), "On the Interpretation of Digital Trace Data in Communication and Social Computing Research". Journal of Broadcasting \& Electronic Media, v. 58, n. 1, pp. 59-75 [Consult. 18-12-2021]. Disponível em https://doi.org/10.1080/08838151.2013.875018 
FUCHS, Stephan (2001), Against Essencialism: A Theory of Culture and Society. Cambridge, Harvard University Press.

FUCHS, Stephan (2009), “The Behavior of Cultural Networks”. Soziale Systeme, v. 15, n. 2, pp. 345-366 [Consult. 18-12-2021]. Disponível em https://soziale-systeme.ch/pdf/sozsys-2009-2_fuchs.pdf

FUCHS, Stephan (2017). "Observing Facts and Values: A Brief Theory and History”. Canadian Review of Sociology/Revue canadienne de sociologie, n. 54, v. 4, pp. 456-467 [Consult. 18-12-2021]. Disponível em https://doi.org/10.1111/cars.12171

FUHSE, Jan (2009), "The Meaning Structure of Social Networks". Sociological Theory, v. 27, n. 1, pp. 51-73 [Consult. 18-12-2021]. Disponível em https://doi.org/10.1111/j.1467-9558.2009.00338.x

FUHSE, Jan (2015a), "Culture and Social Networks" in R. Scott; S. Kosslyn; M. Buchmann (Orgs.). Emerging Trends in the Social and Behavioral Sciences. New Jersey, John Wiley \& Sons.

FUHSE, Jan (2015b). "Theorizing social networks: the relational sociology of and around Harrison White". International Review of Sociology: Revue Internationale de Sociologie, v. 25, n. 1, pp. 15-44 [Consult. 18-12-2021]. Disponível em https://www.tandfonline.com/doi/abs/10.1080/03906701.2014.997968

GIGLIETTO, Fabio; IANELLI, Laura; ROSSI, Luca; VALERIANI, Augusto (2016), "Fakes, News and the Election: A New Taxonomy for the Study of Misleading Information within the Hybrid Media System". Current Sociology, v. 67, n. 4, pp. 625-642 [Consult. 18-12-2021]. Disponível em https://doi.org/10.1177/0011392119837536

HABERMAS, Jürgen (1989), Consciência Moral e Agir Comunicativo. Rio de Janeiro, Tempo Brasileiro.

HORNUNG, Bernd (2019), "The challenges for sociocybernetics". Current Sociology, v. 67, n. 4, pp. 511-526 [Consult. 18-12-2021]. Disponível em https://doi.org/10.1177/0011392119837545

LACLAU, Ernesto; MOUFFE, Chantal (2015), Hegemonia e Estratégia Socialista. São Paulo, Intermeios.

LEYDESDORFF, Loet (2010), "Luhmann Reconsidered: Steps towards an empirical research program in the sociology of communication" in C. Grant (Org.). Beyond Universal Pragmatics: Essays in the Philosophy of Communication. Oxford, Peter Lang.

LEYDESDORFF, Loet (2018), "The differentia specifica of Interhuman Communications: Luhmann and the Sociological Reflection of Information Theory" in G. Dodig-Crnkovic; M. Burgin (Orgs.). Theoretical Information Studies, v. 2. Singapure, World Scientific.

LUHMANN, Niklas (1995), Social Systems: Writing Science. Stanford, Stanford University Press.

LUHMANN, Niklas (2000), The Reality of the Mass Media. Stanford, Stanford University Press.

LUHMANN, Niklas (2006), La sociedad de la sociedad. México, Universidad Iberoamericana.

OLIVEIRA, Thaiane (2020), "Desinformação científica em tempos de crise epistêmica: circulação de teorias da conspiração nas plataformas de mídias sociais". Revista Fronteiras - estudos midiáticos, v. 22, n. 1, pp. 21-35 [Consult. 18-12-2021]. Disponível em https://doi.org/10.4013/fem.2020.221.03

RECUERO, Raquel (2017), Introdução à análise de redes sociais. Salvador, EDUFBA. 
RODRIGUES, Léo Peixoto; NEVES, Fabrício Monteiro (2017), “A Teoria Sistêmica e suas múltiplas possibilidades de teorização”, in L. Rodrigues; F. Neves (Orgs.). Niklas Luhmann: Sistemas Sociais: ensaios teóricos. Porto Alegre, EdiPUCRS.

SOUZA, Queila; QUANDT, Carlos (2008), "Metodologia de Análise de Redes Sociais" in F. Duarte; C. Quandt; Q. Souza (Orgs.). O Tempo das Redes. São Paulo, Perspectiva.

VINHAS, Otávio (2019), Os sentidos da "facada" em Jair Bolsonaro: uma análise de redes culturais online à luz da Teoria dos Sistemas de Niklas Luhmann. Dissertação (Mestrado em Sociologia) Programa de Pós-Graduação em Sociologia, Instituto de Filosofia, Sociologia e Política, Universidade Federal de Pelotas, Pelotas.

VINHAS, Otávio; SAINZ, Nilton; RECUERO, Raquel (2020), “Antagonismos discursivos nas hashtags \#marqueteirosdojair e \#bolsolão no Twitter nas eleições de 2018 no Brasil: contribuições da análise de redes sociais à sociologia digital”. Estudos de Sociologia, v. 25, n. 48. pp. 37-61 [Consult. 18-122021]. Disponível em https://doi.org/10.52780/res.13433

WASSERMAN, Stanley; FAUST, Katherine (1994), Social Network Analysis: methods and aplications. Cambridge, Cambridge University Press.

WHITE, Harrison (2008), Identity and Control, $2^{\mathrm{a}}$ ed. New Jersey, Princeton University Press. 


\begin{abstract}
This article aims to describe the dynamics of the meaning construction regarding the "stabbing" in the former presidential candidate of Brazil, Jair Bolsonaro, on Twitter. Proposing a methodology called Sociocybernetic Network Analysis, we combine computational methods of Social Network Analysis with a theoretical-epistemological constructivist approach to observe the communication in society as a complex operation. Thus, we disclose longitudinally, from three time lapses analyzed, the meaning changes occurred around the stabbing in Jair Bolsonaro on Twitter. We note how, over time, the different perspectives initially produced about the event have been synthesized following a political polarization guided by values. In this way, we concluded that the complexity around the stabbing was organized into two opposing and relational truths: as a fake event or as an attempt of murder.
\end{abstract}

Keywords: stabbing; Jair Bolsonaro; sociocybernetic network analysis; computational social science; twitter.

\title{
Resumen
}

Este artículo tiene por objetivo describir la dinámica de construcción de significados en relación a la "facada" del entonces candidato presidencial, Jair Bolsonaro, en Twitter. Así, proponiendo una metodología de una Análisis Sociocibernética de Redes Sociales, se combinan métodos computacionales de Análisis de Redes Sociales con un enfoque teórico-epistemológico constructivista, enfocado a la comunicación en la sociedad como una operación compleja. Se describe longitudinalmente, por tres lapsos de tempo analizados como ocurrieron cambios em los significados sobre la puñalada en Jair Bolsonaro en Twitter. Se observo cómo, a lo largo del tiempo, las diferentes perspectivas inicialmente producidas se sintetizaron en una polarización política guiada por valores. De esta forma, la complejidad en torno a la puñalada se organizó en dos verdades opuestas: como algo falsificado o como un intento de asesinato.

Palabras clave: puñalada; Jair Bolsonaro; análisis sociocibernética de redes sociales; ciencia social computacional; twitter. 